\title{
Temporary deembedding buyer - supplier relationships: A complexity perspective
}

\author{
Fabian J. Sting ${ }^{1,2}$ | Merieke Stevens ${ }^{2}$ | Murat Tarakci $^{2}$
}

\author{
${ }^{1}$ Faculty of Management, Economics and \\ Social Sciences, University of Cologne, \\ Cologne, Germany \\ ${ }^{2}$ Rotterdam School of Management, \\ Erasmus University, Rotterdam, \\ The Netherlands

\section{Correspondence} \\ Fabian J. Sting, University of Cologne, \\ Albertus-Magnus-Platz, Cologne 50923, \\ Germany. \\ Email: sting@wiso.uni-koeln.de \\ Handling Editors: Anand Nair and Felix \\ Reed-Tsochas
}

Research on buyer-supplier relationships has debated the advantages and disadvantages of embedded relationships. We join this debate by developing theory on the performance implications of relaxing embedded buyer-supplier relationships for a limited period of time - a previously neglected phenomenon we refer to as temporary deembedding. To capture this phenomenon's dynamic and complex nature, we use a combined-method approach. First, we conducted a longitudinal case study of the relationship between Nissan and a strategic first-tier supplier. This case study suggests that temporary deembedding reinvigorates search and leads to higher performance for both the buyer and supplier. Second, we built a computational simulation model using the search perspective from complexity theory to complement the theory grounded in our case study. Our simulations confirm the case findings while shedding additional light on how frequency, duration, and intensity of deembedding affect supply chain performance.

\section{KE Y WOR D S}

buyer-supplier relationships, complexity, embeddedness, combined methods, dyadic and longitudinal study

\section{1 | INTRODUCTION}

Supply chain management is inherently complex and dynamic (Nair, Narasimhan, \& Choi, 2009), because decisions made by one member of the supply chain affect subsequent decisions of other actors. In this dynamic and complex setting, the existence of an "optimized" master plan proves elusive. Instead, supply chain members engage in coevolutionary search to advance and to innovate (Chandrasekaran, Linderman, Sting, \& Benner, 2015; Giannoccaro, 2011; Kim, Choi, \& Skilton, 2015; Levinthal, 1997; Sting \& Loch, 2016), much like BMW's ongoing "Industrie 4.0" initiative to digitalize manufacturing processes and technologies. As part of this initiative, BMW has scanned its entire Rolls Royce plant in Goodwood, UK, within a two-millimeter tolerance. Supply chain gains from such firm-level improvements, however, critically depend on suppliers' compatible interfaces. BMW
COO Zispe reflects: "How will our suppliers connect with these emerging systems?" (Mayer \& Klein, 2015). This quote illustrates how pivotal buyer-supplier relationships are for supply chain innovation and performance (Chen \& Paulraj, 2004; Choi \& Kim, 2008; Kim et al., 2015; Terpend, Tyler, Krause, \& Handfield, 2008). Surprisingly, however, little is known about how buyer-supplier relationships affect coevolutionary search processes, let alone how these processes subsequently drive supply chain performance-the main motivation for this study.

Prior research has shown that closely embedded buyersupplier relationships foster joint problem-solving activities and information exchange (Dyer \& Chu, 2000; Dyer \& Singh, 1998; Gulati \& Sytch, 2007; Uzzi, 1996, 1997), which, in turn, boost buyer performance (e.g., Cachon \& Lariviere, 2005; Choi \& Kim, 2008; Chopra \& Meindl, 2007; Kim et al., 2015). Yet, embedded relationships can also trigger

This is an open access article under the terms of the Creative Commons Attribution License, which permits use, distribution and reproduction in any medium, provided the original work is properly cited.

(c) 2019 The Authors. Journal of Operations Management published by Wiley Periodicals, Inc. on behalf of The Association for Supply Chain Management Inc. 
complacency, limit access to nonredundant information, and lead to poor performance for both the buyer and supplier (Swink \& Zsidisin, 2006; Villena, Revilla, \& Choi, 2011). Consequently, prior research has often advised a constant, moderate degree of embeddedness in buyer-supplier relationships (Gargiulo \& Benassi, 2000; Swink \& Zsidisin, 2006; Villena et al., 2011; Zhou, Zhang, Sheng, Xie, \& Bao, 2014). Despite these advances, current research has three shortcomings. ${ }^{1}$ First, the main focus has been on the buyer's perspective, thus forfeiting a more complete picture of relationship performance for both parties (e.g., Carey, Lawson, \& Krause, 2011; Cousins, Handfield, Lawson, \& Petersen, 2006; Cousins \& Menguc, 2006; Gulati \& Sytch, 2007; Lawson, Tyler, \& Cousins, 2008; Villena et al., 2011; Zhou et al., 2014). Second, perhaps stemming from a strong reliance on crosssectional research designs, studies often overlook the fact that a relationship's level of embeddedness can change over time (for a few exceptions, see Azoulay, Repenning, \& Zuckerman, 2010, Jap \& Anderson, 2007, Saavedra, Reed-Tsochas, \& Uzzi, 2008). Such a static view of buyer-supplier relationships limits our understanding of how these relationships evolve and how different periods in this evolution affect the relationship's search and performance. Third, a prevalent underlying assumption is that an unmalleable relationship structure pegs performance outcomes-an approach that disregards the critical agency aspects of relationships that are deliberately and strategically altered by either party.

Consider Nissan, which cut the embedded ties with its keiretsu suppliers in 1999, many having been affiliated with Nissan since the 1950s (Aoki \& Lennerfors, 2013; Stevens, MacDuffie, \& Helper, 2015). This was a deliberate, strategic choice as part of the so-called "Nissan Revival Plan" (NRP), announced on October 18, 1999. Likewise, five years after deembedding, Nissan decided to rebuild close relationships with several of its suppliers. This illustrates that the static, deterministic conceptualization of buyer-supplier relationships in prior research neglects the fact that firms can strategically relax, and later reinstate, embedded ties-a phenomenon we refer to as temporary deembedding. Developing a theory for temporary deembedding is our goal.

To this end, we employ a combined-method research design - a prerequisite for a broader understanding of complex supply chain management phenomena (Boyer \& Swink, 2008). First, we collected longitudinal and dyadic data at Nissan and a strategic first-tier supplier over a 12-year timespan. We examine how the relationship's embeddedness evolved over time and how that evolution interacted with search and performance. We observe that when the relationship was overembedded, both firms were limited to only incremental improvement initiatives that proved insufficient in breaking the relationship's deadlock that was freezing each firm's innovative potential. Deembedding, in contrast, shifted priority to intrafirm goals over interfirm goals, reinvigorating both Nissan's and the supplier's independent search initiatives. Thus, deembedding helped the supply chain to escape its sticking point. Notably, five years after the abrupt commencement of its deembedding effort, Nissan opted to reembed supply chain ties in order to ensure compatibility among independent search initiatives.

Secondly, to generalize and augment the theory emerging from the case study, we devised a computational model to simulate deembedding in supply chains. The model uses the search notion of complexity theory where a supply chain gradually explores a rugged performance landscape in search of improvement and innovation. Generalizing the case findings, we show that temporarily deembedding supply chain relationships enhances performance by promoting broader search for improvements in complex environments. Nevertheless, deembedding can be a double-edged sword: an intense cut reinvigorates search, but too frequent or prolonged cutting of ties leads to incompatible outcomes that can hamper supply chain performance.

We offer several contributions to research on buyersupplier relationships. First, we investigate the phenomenon of temporary deembedding and develop theory on how it affects supply chain performance. This is important because prevailing research advises balanced degrees of embeddedness (e.g., Uzzi, 1996, 1997; Villena et al., 2011; Zhou et al., 2014), while largely ignoring the question of how an ideal balance can be achieved. We address this issue by proposing a dynamic balance. More specifically, we argue that the level of embeddedness can be altered dynamically over time to reinvigorate supply chain innovation and performance. Second, we integrate supply chain embeddedness with complexity theory and its fundamental notion of search. The search perspective offers new theoretical insights on the outcomes of buyersupplier relationships that go beyond the current explanations based on transaction cost economics (e.g., Williamson, 1985), the relational view (e.g., Dyer \& Singh, 1998), and social network theory (e.g., Gulati \& Sytch, 2007; Uzzi, 1996, 1997). Third, we propose an agency view of buyer-supplier relationships. This view qualifies extant approaches that consider these relationships as either relatively stable (e.g., Villena et al., 2011; Zhou et al., 2014) or as following a presaged course (e.g., Jap \& Anderson, 2007; Vanpoucke, Vereecke, \& Boyer, 2014). Instead, we explicitly recognize the agency of firms in deliberately and strategically tuning their relationships. Supply chain researchers can benefit from this fresh agency viewpoint, because it sheds light on the pivotal role of endogenous changes in buyer-supplier relationships.

\section{2 | LITERATURE REVIEW}

Complexity theory, with its central notion of search (Cyert \& March, 1963), describes how organizations generate innovations 
when facing high complexity (Levinthal \& March, 1993; Siggelkow \& Rivkin, 2005), that is, when many choices interact in nonsimple ways (Simon, 1962). Supply chains exemplify such complexity because numerous decisions interact among supply chain members, and organizations cannot fully oversee or understand, let alone globally optimize, all decisions simultaneously (Levinthal \& Warglien, 1999). Instead, organizations dynamically explore the landscape of possible actions in an evolutionary, path-dependent search process. While search processes have been discussed in complex manufacturing and high-tech settings (e.g., Chandrasekaran et al., 2015; Sting \& Loch, 2016), to the best of our knowledge this lens has not been applied to supply chain embeddedness. Given the dynamic, coevolutionary, and complex nature of buyer-supplier relationships, this omission is surprising because the strength of such relationships is likely to affect the way supply chain members search jointly (Kim et al., 2015).

Buyer-supplier collaboration and knowledge exchange were shown to be key in managing complexity (Kim et al., 2015). Such relationships can vary from strongly to weakly embedded. Embeddedness strength is shaped by structural, relational, and cognitive factors. Structural factors include joint projects, operational assistance, and cross shareholdings (Clark \& Fujimoto, 1991). Relational elements encompass friendship, goodwill, and respect (Uzzi, 1996, 1997). Cognitive factors consist of shared meaning, expectations, and vision (Nahapiet \& Ghoshal, 1998).

We investigate the phenomenon of temporary deembedding of buyer-supplier relationships defined as relaxing embeddedness for a limited period of time. Temporary deembedding thus implies the dissolution and subsequent resumption of embedded ties. This concept does not denote the state of a relationship but, rather, a process of deliberately altering the relationship. In this way, temporary deembedding advances prior research by offering a dynamic and malleable viewpoint.

To delineate the nomological network of embeddedness and temporary deembedding, we reviewed related concepts such as reciprocal interdependence (Thompson, 1967), near decomposability (Simon, 1962), weak ties (Granovetter, 1973), and loose coupling (Orton \& Weick, 1990). Reciprocal interdependence refers to one party's decisions influencing another party's decisions; near decomposability entails the grouping of decisions that are strongly interdependent. These concepts thus tally strengths of interdependence in a system, whereas embeddedness describes relationship strength. As such, embeddedness is composed of structural (e.g., concentration of business and equity stakes), relational (e.g., frequency of interaction), and cognitive (e.g., shared norms) dimensions. Loose versus tight coupling refers solely to the degree of operational integration, hereby capturing only the structural dimension of embeddedness (for a recent discussion, see Kim et al., 2015). Therefore, embeddedness uniquely offers sufficient conceptual breadth. What is more, embeddedness, coupling, and tie strength all denote merely the state of a buyer-supplier relationship, while deembedding refers to changing it. In the following sections, we develop theory on temporary deembedding.

\section{3 | CASE SELECTION AND METHOD}

We conducted a longitudinal, inductive case study of the relationship between Nissan and one of its strategic first-tier suppliers (referred to as "the supplier") during the period 1999-2012. ${ }^{2}$ Our unit of analysis is the relationship between Nissan and the supplier. Our approach allowed us to trace different periods of embeddedness in real time while assessing the improvement and performance implications for both the buyer and the supplier.

\section{1 | Case selection}

We identified Nissan as a critical setting (Barratt, Choi, \& $\mathrm{Li}, 2011)$, because Nissan deliberately and publicly adjusted the level of embeddedness with its suppliers during the period of our study. This adjustment targeted its entire supply base: Nissan purposefully discontinued the "Japanese way" of managing supplier relationships-a practice that has played a prominent role in the literature on close coordination and that had received admiration since the 1980s when Japanese carmakers overtook their American counterparts.

We selected one supplier across different embedding periods in order to gain in-depth understanding of one temporary deembedding process. Furthermore, we selected the supplier ourselves rather than asking Nissan, in order to avoid social desirability bias. Because we assured anonymity to the supplier, we cannot disclose the component delivered by the supplier. Our sampling criterion was that both companies had to view their relationship as strategic. First, from Nissan's perspective, the supplied component's strategic relevance is reflected by its "just-in-time" and "in-sequence" delivery from colocated supplier factories directly to Nissan's production line. Also, the business volume between Nissan and the supplier has been substantial throughout our research period. During the period preceding the NRP, the supplier accounted for approximately one third of Nissan's domestic demand for this particular component. Moreover, there is a direct interface between the end user of the car and the component, which has an important impact on driving experience. Second, from the supplier's perspective, Nissan was its most important customer. During the 1990s, Nissan accounted for one third of the supplier's production volume. 
To encourage supplier interviewees to talk freely, we did not mention their company's name during our interviews with Nissan, choosing instead to query Nissan interviewees about all three main suppliers of the component in question. The length and in-depth nature of our interviews enabled us to gather sufficient information from Nissan about our focal supplier.

\section{2 | Data collection}

Our data consist of official company reports of both Nissan and the supplier; patent data; as well as coverage in the media and business press. To better understand deembedding at the systemic level, we gathered such data also from other Nissan suppliers. We collected these data continuously from the announcement of the NRP in 1999 up to 2012. In addition, we conducted face-to-face interviews over a 12 -year period. At both Nissan and at the supplier, we interviewed key employees central to the relationship-several times when needed. With the exception of Renault-Nissan's CEO Carlos Ghosn, all interviewees spoke on the condition of strict anonymity. Table 1 provides a summary of our interviews.

These interviews were conducted by the second author who is fluent in Japanese. The interviews with CEO Carlos Ghosn and one non-Japanese Nissan employee were conducted in English in Japan. Two senior executives and three senior purchasing managers were interviewed in English in France. All other interviews were conducted in Japan in Japanese. We designed the interview protocol in English and translated it into Japanese. A native Japanese speaker translated the protocol back into English to fix minor issues. The duration of the semistructured interviews varied between $30 \mathrm{~min}$ and $5 \mathrm{hr}$, leaving ample room for new topics to arise.

Most interviews were taped, and all taped interviews were transcribed verbatim the same day. When interviewees declined to be taped, detailed interview notes were taken. Japanese interviews were translated into English by the interviewing author with a Japanese native speaker subsequently

TABLE 1 Overview of interviews

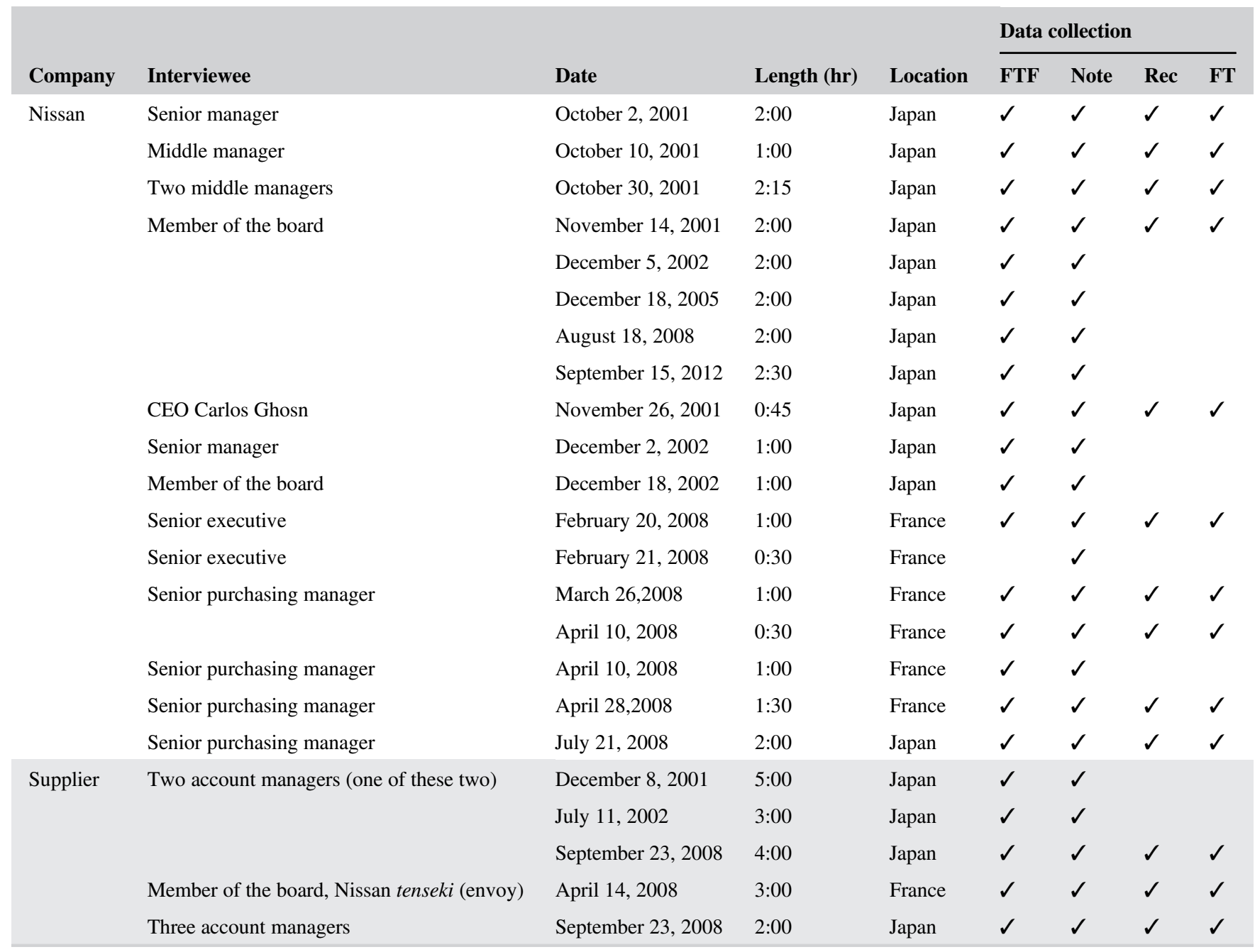

Note. FT: full transcript made from recording; FTF: face-to-face interview; Note: extensive notes taken during the interview; Rec: full recording made of interview. 
double-checking the translations of the main episodes of the recordings. Any unclear content was resolved during subsequent meetings or through follow-up phone calls or emails.

\section{3 | Data analysis}

Our interest in embeddedness took hold when learning through the media of Nissan's deembedding moves in 1999. As a first step, our study analyzed Nissan's public announcements as well as media coverage of the NRP. Recurring mention of "destruction of the keiretsu" and references to Ghosn as the "keiretsu killer" pointed us to extant research on the keiretsu approach to organizing the supply chain (e.g., Dyer, 1996; Nishiguchi, 1994; Sako \& Helper, 1998). Based on these sources and our interest in supply chain relationship performance, we drafted our interview protocol of semistructured questions (see Appendix A). Our aim was to capture all main dimensions of buyer-supplier relations while allowing enough room for elaboration as well as the introduction of new topics by our interviewees. Apart from data about the pre-NRP period, all information was collected in real time. We asked respondents about the period "before 1999" during all interview rounds. We compared the responses given in each period about the pre-1999 period with each other and found no noticeable differences, implying that retrospective error is not a concern with respect to our understanding of this period.

The initial analysis of our interview data revealed two major triggering events that "bracket" the different periods of our study (Langley, 1999). The first triggering event was the announcement of the NRP by Ghosn on October 18, 1999. During this speech, Ghosn made a sharp distinction between what had prevailed in the past and what would come in the future, indicating that Nissan was at a turning point. The second triggering event arose on November 18, 2004, when Ghosn at a meeting with suppliers expressed his renewed appreciation of keiretsu. These two triggering events segment our data set into three periods that each indicates different levels of embeddedness: (a) pre-NRP during which we found the relation between Nissan and its supplier to be closely embedded; (b) 2000-2004 when Nissan effectively deembedded the relationship; and (c) the period from 2004 onward when attempts at reembedding were undertaken.

We proceeded with an in-depth analysis of each of these periods. Following Gioia, Corley, and Hamilton (2012), we first relied on "open coding" by adhering closely to informant terms. We grouped similar remarks together to come to our first-order codes. In the next step, we axially coded these informant-centric first-order codes, resulting in our secondorder codes that capture commonalities in our first-order codes. We proceeded to substantive coding of our data into aggregate dimensions, using concepts from the buyer-supplier relationships and search literature as a point of reference.

\section{4 | CASE FINDINGS}

This section discusses the three embeddedness periods: (a) embedding, (b) deembedding, and (c) reembedding. We also detail the two triggering events that mark these periods, describing the relationship and the outcomes for both Nissan and the supplier.

\section{1 | Before NRP: Embedded relationship}

\subsection{1 | Relationship}

A well-known characteristic of the keiretsu approach is shareholding in suppliers; a system-wide practice also followed by Nissan (Cusumano, 1985). Our case is no exception: in the preNRP period Nissan held a $20 \%$ equity stake in the supplier. Figure 1 depicts Nissan's ownership in the supplier as well as in 20 other strategic first-tier keiretsu suppliers. We observe that Nissan's average equity ownership in any of its suppliers did not change drastically before the NRP. Another characteristic of the keiretsu system is the colocation of supplier factories with buyer factories. Our case also exemplifies this practice, and the first plant and headquarters of the supplier were built in the

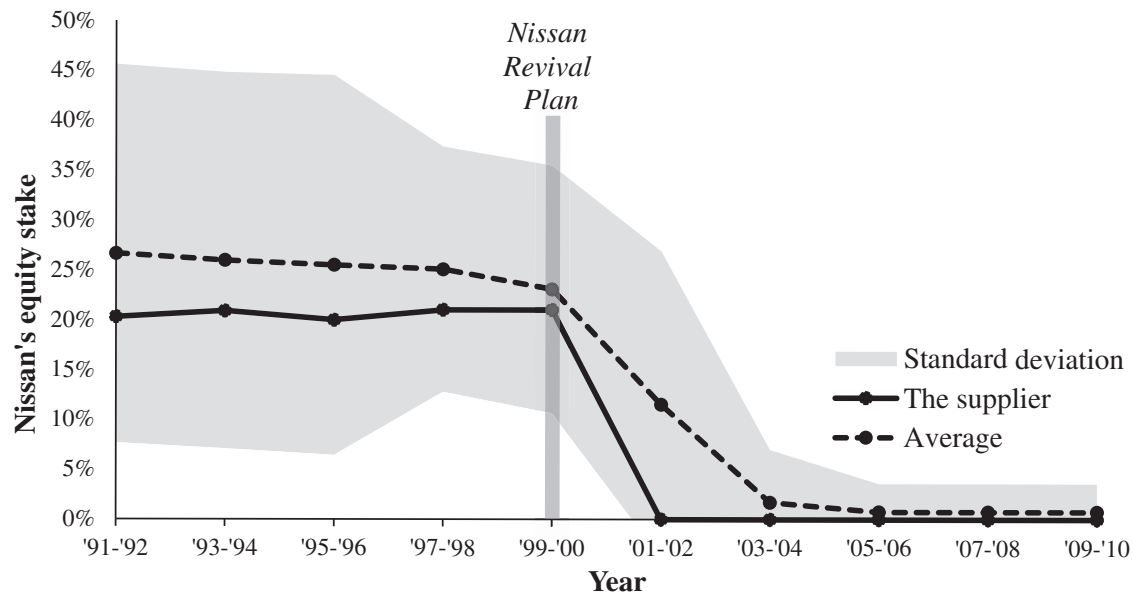

F I G URE 1 Nissan's equity ownership in 20 strategic suppliers. Shaded area indicates the $S D$ of ownership. Dotted line represents equity in our case supplier. Data were retrieved from Nissan's and suppliers' official company documents 
direct vicinity of a Nissan factory. As the relationship evolved, Nissan assisted the supplier in opening colocated production facilities at all of Nissan's six domestic mass production plants.

Also, Nissan dedicated senior purchasing managers to serving ties with each of its affiliated suppliers. When nearing retirement, these purchasing managers moved from Nissan to comfortable positions at these suppliers - a practice known in Japan as tenseki. This practice helped Nissan because the senior purchasers would switch to the supplier's payroll, while the supplier benefitted from the close ties with Nissan of these ex-Nissan envoys. Having assigned purchasing managers to a supplier firm rather than to a component group often incentivized Nissan purchasers to champion "their supplier". Suppliers, in turn, invested heavily in ensuring that "their buyer" remained closely tied to them. By meeting for after-hours drinks, dinner, or overnight trips (including trips abroad), and through personal gifts from the supplier, work duties and social lives became deeply entangled.

We also observed that Nissan and the supplier referred to the supplier as Nissan-kei (Nissan group). ${ }^{3}$ In addition, the keiretsu practice of referring to Nissan as oyagaisha (parent firm) or oyabun (parent part) and to the supplier as kogaisha (child firm) or kobun (child part) was used. Amplifying the family analogy, Nissan's wholly owned supplier was dubbed Nissan's first wife, while the supplier called itself Nissan's second wife (using English terms). The usage of familial terms signaled a farreaching commitment where each party internalized a prescribed relationship-serving role to enact. To illustrate, our interviewees reflected on the keiretsu period with comments such as "this is the way it always has been," or "we simply belong to Nissan."

\subsubsection{Improvement and innovation initiatives}

Nissan's focus was improving manufacturing excellence as a goal for its supply chain relationships in themselves, expecting suppliers to improve exclusively through joint, incremental process advancements (kaizen). In case of the focal supplier, it would first be awarded a specific contract and subsequently be expected to achieve cost reduction targetsall within the dominant design and in concert with Nissan. Informants at both sides of the relationship reported joint improvement initiatives, noting that such improvement initiatives delivered incremental outcomes (i.e., adapting to smooth out existing problems in the production system) rather than radical or proactive ones (i.e., generating ideas that would advance the supplier's technological capabilities). Cross-organizational improvement teams staffed by senior individuals from both partners focused on retaining harmony (wa) rather than on generating radical ideas. Thus, joint efforts were geared toward preserving the dominant design at a loss of momentum as reflected by the supply chain products' reputation of "smelling of old men" - an image often cited by our interviewees both at the supplier and at Nissan.
Our interviewees at the supplier stressed that during the embedded period, they were obliged to obey their "parent" and follow its course. This, in turn, relieved the supplier of making strategic decisions such as which technologies or markets to pursue. A manager at the supplier diagnosed the technological standstill in the following way:

With shigarami [strong bonds] in keiretsu, it is really hard to create new technology, and this is needed to win in the new market. Shigarami inhibits progress.

At the systemic level, internal supplier championing at Nissan frequently led to the rejection of new suppliers and technologies by Nissan's purchasing department (Sugiyama, 2002). Beyond the focal relationship, this "lock-in" was evidenced by Nissan's refusal during its downturn to change its supply base in terms of the number of suppliers. This was the case even when production at its seven domestic factories dropped to about $50 \%$ of capacity during the 1990s. Illustrating this point, a senior executive at Nissan described the snares of the gridlock into which both Nissan and its supplier were trapped:

The pre-99 situation was unsustainable in its coziness and inefficiency because of a lack of tension-it was far too comfortable. There was no tension to promote performance improvement. In a situation where relationships will be too long-term, there are barriers to entry for some of the new suppliers or more agile suppliers. Can you imagine in this situation [...] the sourcing of components in low-cost countries, or leadingcost countries? It would not have happened because there is no drive-no impetus to change.

One startling drawback of this combined technological and relational lock-in was Nissan forgoing the technological opportunity of hybrid electric engines. Main rival Toyota had launched the hybrid electric Prius in Japan in 1997, but Nissan did not have the required capabilities in-house, nor in its keiretsu, to enter this market. ${ }^{4}$

Ultimately, Nissan's embedded supplier relationships coincided with poor efficiency and slowing growth. For example, Ghosn said during our 2001 interview that a benchmark study of component prices revealed that Nissan had been paying 20-25\% more for its parts than its alliance partner Renault. These observations became the basis for the subsequent radical reform.

\section{2 | NRP: Deembedding}

Nissan's belief that keiretsu-style relations had become a liability led it to craft the NRP. At its announcement, Ghosn 
stated one maxim: "No sacred cows, no taboos, no constraints." Nissan's expectations regarding the supplier had changed dramatically, as summarized by a senior Nissan purchasing manager:

The ability to deliver high quality products at a low price now really has become the responsibility of suppliers. Nissan is not willing to just pour money into the suppliers anymore ... QCD [Quality Cost Delivery] is the basis of the sourcing decision. The trend is very much discrete: "Do you want this? You are in straightforward competition-best price, you get it; otherwise, you won't."

\subsection{1 | Relationship}

Nissan divested shares in all but four of 1,394 affiliated firms (see Figure 1). During our interview with Ghosn in 2001, he reflected on shareholding in keiretsu times the following way:

Before, the relationships were confused by shareholdings. You felt obliged to buy from a company because you owned part of this company.

Nissan further announced that the total number of component suppliers would be reduced to 600. These remaining suppliers were obliged to reduce the price of their parts delivered to Nissan by $20 \%$ within three years. Our focal supplier was even asked for a $26 \%$ price reduction of its components. Also at the dyadic level radical changes were executed. Pre-NRP practices of Nissan engineers aiding kaizen process improvement activities at the supplier's facilities were abolished. Likewise, Nissan no longer trained supplier personnel at its own facilities. Furthermore, some supplier facilities near Nissan factories were shut down by the supplier.

After-hours socializing among Nissan purchasers and supplier representatives was banned by Nissan, which severely affected personal relationships. Mid-year gifts (o-chügen) traditionally exchanged in Japan with key business contacts were shunned by Nissan, poignantly symbolizing a rejection of the "Japanese way." Such radical changes earned Ghosn the nickname "keiretsu killer" (Nezu, 2000). Ghosn made clear that preferential treatment of suppliers was now deemed a bad practice. According to Ghosn:

Sourcing decisions in all categories will be strictly based on credible performance commitment. This clearly means that sourcing from our affiliates will be no exception to this guideline.
In addition, Nissan's purchasing department was completely overhauled. The previous structure with purchasers dedicated to one specific supplier was replaced with purchasers in charge of component groups. As a result of this systemwide change, the supplier lost its champion at Nissan and eventually had to negotiate with a French purchaser in Paris who had broader knowledge of all offers in the field. Because socialization between purchasers and supplier personnel was strictly forbidden during this period, in one stroke, the supplier lost its access to information regarding developments at Nissan.

Our interviewees at the supplier described the relationship with Nissan as having changed from a parent-child relationship to "having become adult" (otona ni natta). This change was also reflected in the business language used. During our interviews, we noted that interviewees at the supplier referred to the pre-NRP period as Nissan "offering" or "giving" them business; post-NRP, they talk about "winning" business.

\subsubsection{Improvement and innovation initiatives}

In its efforts to build a globally competitive supply base, Nissan committed itself to evaluating any supplier, incumbent, and new, according to exactly the same standards. Our focal supplier is a case in point. Nissan no longer promised to allocate business, let alone guarantee survival, irrespective of the supplier's performance. Instead, Nissan sequentially brought in two new suppliers for this component (one immediately, based in the United States, another two years later, based in Europe). Nissan replaced its pre-NRP focus on manufacturing excellence with a stringent focus on profit. By expanding its supply base to new markets, Nissan hoped to further enhance opportunities for both efficiency improvements as well as innovation. According to a senior purchasing manager:

We have a very good manufacturing system we should hold on to, but not at all costs. And that is really what was happening ... If we kept that pure manufacturing focus rather than a business and a profit focus, we wouldn't [be] building plants in Chennai, in Morocco, in Russia-I doubt it. So I think it [the NRP] has taken that focus away from a pure manufacturing excellence.

The supplier responded immediately after the NRP had taken effect by channeling its improvement activities into its own "Survival Plan." This plan was a strategic roadmap to "design products that cost less." First, the plan outlined the supplier's increased contribution to product development and design. Incorporating these value-added activities was paired with building in-house capabilities in computer aided design 
(CAD). A manager at the supplier explained that before the NRP, they relied on their second-tier suppliers for design. After the NRP, they increased their investments in R\&D and prototyping. Second, the supplier's survival plan stipulated efficiency enhancing improvement initiatives such as redesigning plant layouts, introducing manufacturing line flexibility, implementing tightly synchronized material flows, reducing inventories, as well as deploying zero-defect quality goals. These measures aimed at reducing direct labor cost by $30 \%$ within three years. During the first year, a $16 \%$ reduction in these costs was achieved, representing a large efficiency gain while increasing output in the same period. Third, the supplier consolidated its own supplier base. For example, for a key component the supplier's own supply base was reduced from 16 suppliers in 1999 to four in 2002. Selection of second-tier suppliers was based not only on price but also on technological capabilities. In addition, all sub-suppliers now had to use CAD technology. Noncompliance would trigger deselection, as stated by a supplier interviewee in 2001 .

These measures, combined with new buying alliances with similar companies, were expected to reduce the supplier's purchasing costs by $30 \%$ in the ensuing three years. The implementation of the survival plan ultimately enabled the supplier to achieve the $26 \%$ cost reduction demanded by its key buyer Nissan. So, while Nissan strove for a broader absorption of technology and searched for new partners, the supplier exerted efforts to achieve efficiency improvement and capability development geared toward becoming a viable, self-reliant entity.

\section{3 | Reembedding}

A few years into the NRP, Nissan's more flexible and efficient approach to supplier selection began to face the strain of weakened coordination. One striking example was the Japan-wide steel shortage in November 2004. Nissan's domestic competitors all received their ordered quantities and could continue production as planned (Ibison \& Fifield, 2004). Nissan, however, had cut the number of steel suppliers from five to two during the NRP and had drastically decreased the volume purchased from its previous keiretsu steel supplier to below 10\% (Itoh, 2001). Consequently, Nissan had to stop production at the three factories for five days in November and December 2004 as its orders were not fulfilled. This clearly showed a break with the past with regards to supplier commitment to Nissan. A second important reason for Nissan to seek intensified coordination was to pursue its strategic aim of introducing 28 new models in the period 2005-2008. Because of "cooled down" relations with suppliers, Nissan feared it was missing out on information that would spur cheaper production (Nikkei Industry Journal,
January 13, 2005). Consequently, Nissan became increasingly concerned about reduced supplier responsiveness. According to a senior Nissan purchasing official:

In the past ... we could ask suppliers without a commercial negotiation "Can you make sure that you work Saturday morning this week because we just had a breakdown?" or "We want to bring some visitors around-sorry you got only halfan-hour's notice - they'll be arriving at 4 o'clock." But we probably have seen some deterioration in responsiveness to change. Now, it's a bit more formal: "Who is paying for Saturday morning, please, before we commit?" "Is this visitor really important?" Or: "We are too busy, can we put it off to next week?" Or: "Can't you tell him to go see a different supplier?"

\subsection{1 | Relationship}

These developments triggered the second change in the relationship: a reappreciation of embedded ties with suppliers announced by Ghosn at a meeting with suppliers on November 18, 2004. According to Ghosn: "from now on, it is necessary for Nissan to strengthen cooperative ties [with suppliers]" (Nikkei Industry Journal, January 13, 2005). Ghosn also publicly stated a reappreciation of the keiretsu approach: "Not everything about the keiretsu was wrong. It simply did not function properly at Nissan in the past. With Nissan's subsidiaries, the keiretsu system was too cozy" (Mikawa \& Okudaira, 2005).

Subsequently, a number of initiatives were aimed at strengthening the relationship with suppliers. First, through the alliance supplier improvement program (ASIP), Nissan began to offer specialized, on-site production process support to its suppliers. Next, under the telling umbrella term of THaNKS: (Trustful, Harmonious, Nissan Kaizen activities with Suppliers) Nissan actively pursued strengthening relations with suppliers. Departing sharply from NRP practices and returning to the keiretsu approach, these initiatives were focused on achieving goals cooperatively. For example, Nissan explicitly stated improvement of trust with suppliers as a goal of these efforts. It organized combined purchasing of raw materials, shared transportation of parts, as well as supplier access to its own logistics system. Notably, a central tenet of the keiretsu approach made its comeback - at least on paper: the benefits of improvements under the THaNKS initiative would be shared with suppliers on a 50:50 basis.

As a platform to foster renewed collaboration, Nissan used the Renault Nissan Purchasing Organization (RNPO, founded in 2001) made up of panels for all main automotive 
component groups. Selection procedures to become an RNPO supplier were open to all suppliers-a policy in support of Nissan's wish for unrestricted, flexible, and global selection. But once component panels were formed, Nissan asserted a more collaborative stance. For example, to encourage our focal supplier-who has been on the panel since RNPO's inception-to invest in colocated facilities abroad, Nissan offered contract packages for several factories in the same countries and recommended local partners to the supplier with which joint ventures could be forged.

To further underscore its change in direction, Ghosn on May 13, 2008, announced Nissan's third business plan postNRP, called Growth and Trust 2012 (GT2012). During the presentation of GT2012, strong relationships with suppliers were portrayed as the foundation from which Nissan would improve its productivity. ${ }^{5}$

The supplier during this period opened 10 factories in the direct vicinity of Nissan's global production facilities in Asia, South America, and the United States. By way of comparison, during the five-year deembedding period they had only opened one colocated factory in China. To build colocated plants the supplier would turn to Nissan for assistance in matters such as the acquisition of land and identifying competitive second-tier suppliers. New supplier facilities were mostly set up in joint ventures with partners suggested by Nissan. According to our supplier interviewees, Nissan recognized the cost involved in opening new production facilities, and, in combination with a continuous cost reduction target, accepted "a certain kind of responsibility" by typically ensuring business for at least five years.

During this time, the supplier also opened engineering facilities in France close to the technical center of Nissan's partner Renault. In Japan, the supplier started to attend design and engineering meetings organized by Nissan at Nissan's technical center. Amongst our supplier interviewees, the belief that Nissan had regained technological capabilities that were worthwhile learning from started to take root again. Moreover, they believed Nissan's initiatives to regain a close relationship were not only sincere, but would also directly benefit the supplier because Nissan had successfully fended off its crisis and seemed to be on a solid trajectory of recovery, particularly abroad. One supplier interviewee explained their interest in renewed closeness to Nissan in the following way:

Before, [Nissan] purchasing people were very lazy. With the arrival of Carlos Ghosn they all changed their way of working dramatically. And that was a very good thing for the company I think, because Nissan is very profitable today.

Some of our interviewees at the supplier however were skeptical about Nissan's attempts at closer coordination. They viewed these initiatives as a Trojan horse that would give Nissan access to their facilities and information systems, which they believed would be used to enforce further cost reductions. According to one of our interviewees at the supplier:

Nissan wants to have transparency to the supplier, but not the other way. They want to have transparency to find an opportunity for reducing costs. That's the motivation for asking us to be transparent.

As exemplified by the two quotes above, supplier employees' opinions on their firm's reembedding with Nissan were mixed. Concluding, we see that despite the reservations, the supplier took the opportunity to expand internationally alongside Nissan and engaged more frequently and closely with Nissan.

\subsubsection{Improvement and innovation initiatives}

In addition to Nissan's operational assistance to suppliers abroad and in Japan, this period saw a more active exchange of information with its suppliers. With regards to our focal dyad, Nissan invited supplier employees to its technical center for bilateral discussions on specific products alongside general training and brainstorming sessions. At this time, our interviewees at the supplier were no longer outright dismissive of Nissan's offers to dispatch engineers to their sites.

Importantly, the supplier's focus shifted to the needs of the end customer - a change made clear in the supplier's official "corporate philosophy" as featured in its brochures and at its website. Consequently, Nissan and the supplier geared their improvement and innovation initiatives toward a common goal, customer satisfaction, they did not share during the NRP period.

It should be noted, however, that during this time Nissan did not relieve its cost pressure on the supplier. Final decisions on supplier selection were made, as in the deembedding period, based on tough cost performance and price criteria. That being said, the RNPO panel membership embodied a medium to longer-term oriented collaborative ethos rather than the per-contract, transactional approach of the previous period, to reflect the emerging belief that joint improvement initiatives could benefit the relationship's performance.

\section{4 | Synopsis: The three periods}

The end of the embedding period was marked by ailing performance for both Nissan and the supplier. During that time, improvement as well as innovation initiatives by both partners had stalled. Nissan narrowly focused (and enforced its supplier's focus) on manufacturing excellence to the detriment of innovation initiatives, resulting in poor cost performance and 
uncompetitive product design. The supplier was not able to effectively forge substantial changes because it did not contribute any new technologies. More radical innovations, deemed disturbing to the relationship's status quo, were shunned. Thus, neither partner strove to liberate the relationship's deadlocked situation and generate more significant innovations. With the relationship having settled in a mutually acceptable-yet globally inferior-configuration, collaborative initiatives were no longer sufficient to advance the relationship's performance, resulting in a worrisome decline.

We find that when embeddedness was temporarily relaxed by the NRP, both partners were spurred to independently search for improvement and innovation. Both succeeded in improving individual results, with Nissan enlisting a broader set of suppliers that offered new technologies. The supplier, in turn, was able to focus on advancing its own R\&D capabilities, to streamline its processes free of Nissan's stifling protection, and to seek new customers. This independent search performed by both partners unleashed creativity and helped the relationship dissolve its deadlock.

As Nissan's post-NRP performance improvements started to plateau, it sought to reembed its suppliers. Nissan could no longer reap the benefits of coordinated actions and was seeking to resume mutually aligned innovation initiatives. According to a senior Nissan purchasing official:

We've bottomed out now in terms of the competitive, destructible, short-term approach. ... If Nissan thinks it can survive, thrive, and prosper at the expense of suppliers, then clearly that's not the case.

Considering all three periods together, the temporary relaxation reinvigorated supply chain performance, because it sparked improvement and innovation activity.

Clearly, Nissan did not revert to the identical pre-NRP constellation during reembedding, which is not surprising given technological change, demand shifts, turnover of key personnel, and so forth that any firm would most likely face during a 12-year period. Nonetheless, the keiretsu past was deliberately invoked in Nissan's efforts to regain closer coordination with suppliers. According to one of our Nissan interviewees:

[Nissan is] starting to think about going back to some of the pre-1999 long-term-ism rather than what was subsequently. ... [There is] a realization now that maybe we have exhausted the other approach. And as these things tend to be quite cyclical we start talking more about trust, more about partnership, more about long-term relationships. ... It won't look like what we knew from pre 99 , but . . there is a realization now that we've caught up from a benchmark position and we now need to decide how we can move forward and how we can be far more constructive.

Patent data, despite its flaws (Cohen, 2010), may serve as a proxy to depict the observed changed pattern of improvement and innovation initiatives. Figure 2 plots the number of patents Nissan and the supplier were granted for the focal component during the timeframe. Especially when considering the relationship's total number of patents granted (dotted curve), one can observe that the relationship's innovation performance slowed to a minimum just prior to the 1999 NRP with a later recovery and rise until 2006.

The relationship's innovation performance is reflected in bottom-line financial performances: Figure 3 illustrates Nissan's turnaround in terms of both profits and revenues in pre- and post-NRP years. Purchasing and supplier relationships contributed the lion's share to this increase in profit. For instance, during fiscal year 2002, net savings generated by Nissan's purchasing initiatives were estimated by Ghosn to be 227 billion yen. The supplier's profitability had been
F I G U RE 2 Nissan's and the supplier's filed and granted patents over time. The data were retrieved from Google's patent database

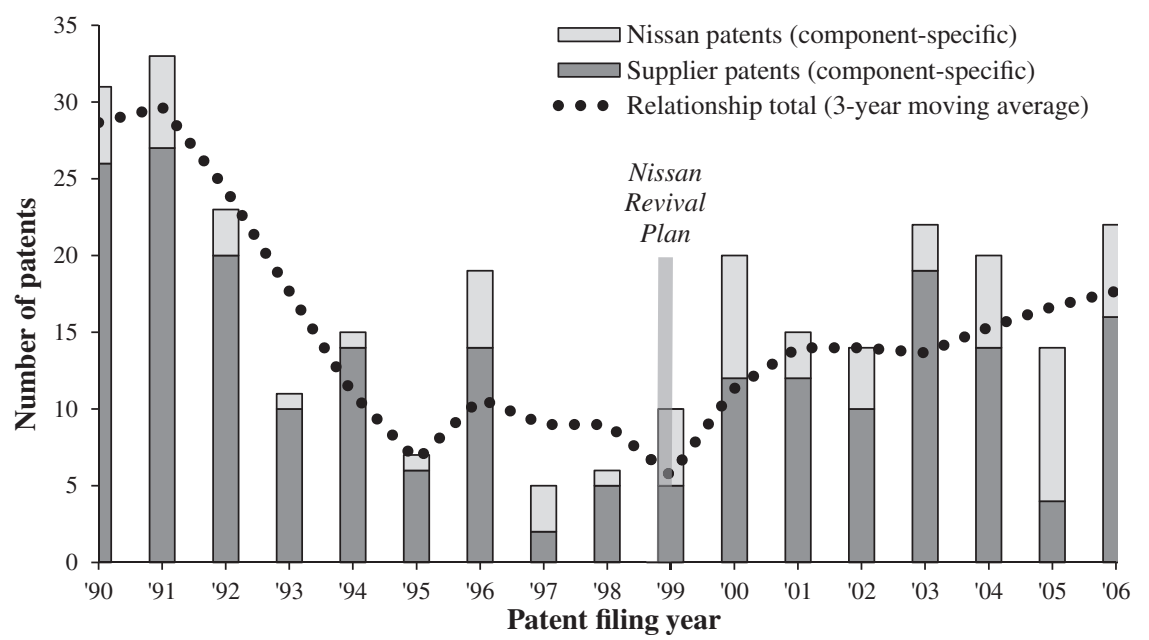




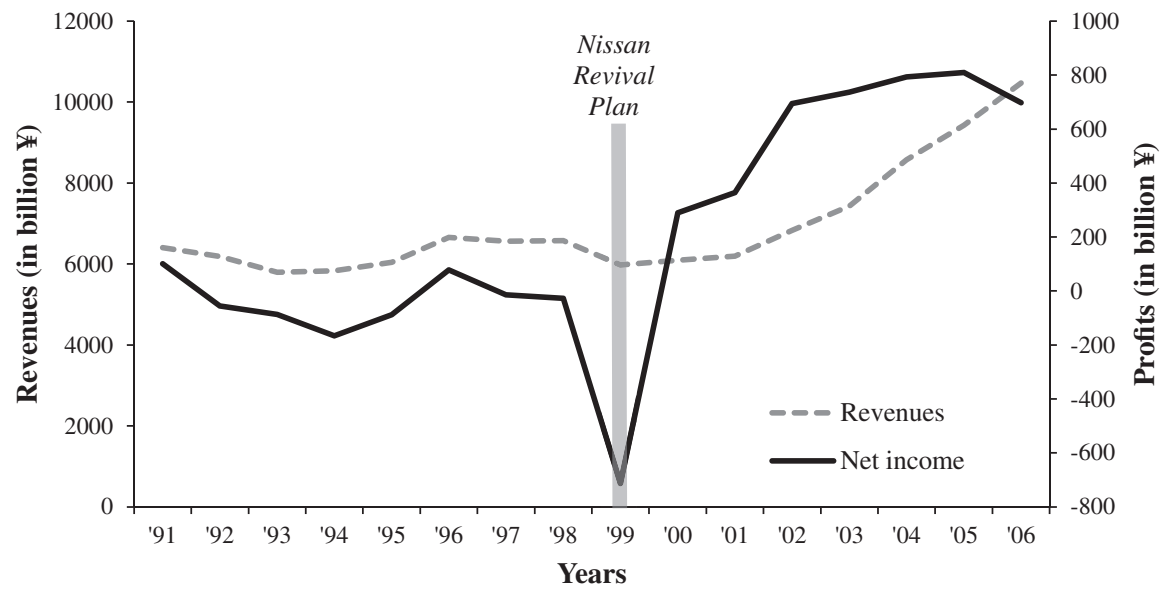

F I G U RE 3 Nissan's revenues and profits over time. The data were retrieved from Nissan's Japanese financial statements and Thompson One database ailing during the 1990s and faded briefly with the NRP, resulting in a net debt for the first time in its history in 2001 and 2002. Yet, improvement initiatives helped the supplier recover, and even surpass, its pre-NRP profit levels from 2003 onward. Thus, Nissan's recovery was not merely resulting from a zero-sum game at the cost of the supplier. Rather, performance improved for both members of the relationship. ${ }^{6}$

Based on this synopsis of the three periods, we formulate the following proposition:

Proposition 1: A temporary relaxation of buyersupplier embeddedness can aid overall supply chain performance via reinvigorated improvement and innovation initiatives.

Culminating in Proposition 1, the case offers important insights into the deembedding phenomenon. Yet, the case alone leaves open important questions of how often, how long, and at what intensity temporary deembedding helps. Therefore, by complementing the case with a simulation model, we aim to generalize and augment the theory we built on the deembedding phenomenon. Importantly, this model is grounded in the case by capturing the following core elements of the case study: (a) the complex technological environment that the focal supply chain faces, (b) a supply chain relationship that can be either in an embedded or in a deembedded state, and (c) the phenomenon of temporary deembedding.

\section{5 | A COMPUTATIONAL SIMULATION MODEL OF DEEMBEDDING}

Our model is grounded in the case and parsimoniously represents its core elements: (a) a supply chain's search on a complex technological environment by using canonical performance landscapes, (b) the supply chain is constituted by a relationship between a buyer firm and a supplier firm in either an embedded or a deembedded state, and; (c) temporary deembedding is a dynamic process that changes an embedded supply chain relationship into a deembedded and then back to a reembedded one. In the following, we describe how these three core elements are operationalized in our model.

\section{1 | Supply chain search on a performance landscape}

We build a variant of Kauffman's (1993) NK model to represent a supply chain's search for performance in a complex technological environment. The NK model is a widely used method to model complex organizational problem solving (e.g., Chandrasekaran et al., 2015; Giannoccaro, 2011; Giannoccaro \& Nair, 2016; Siggelkow \& Rivkin, 2005). In our application of this model, $N$ represents the number of decisions made in the supply chain. For instance, one typical decision could consider the material flows at the first-tier supplier to be organized following a push or pull logic. In another decision, the buyer undertakes quality controls.

Following the standard NK model, each of these decisions $d_{\mathrm{i}}$ is assumed to be binary, that is, $d_{i} \in\{0,1\}$, for $i=1, \ldots, N$. In a supply chain context, decisions such as these are typically distributed between suppliers and buyers. For the sake of parsimony, we assume that the supplier has to make the first $N / 2$ decisions $\mathbf{d}_{S}=\left(\mathrm{d}_{1}, \ldots, \mathrm{d}_{i}, \ldots, \mathrm{d}_{N / 2}\right)$, whereas the buyer exercises the other $N / 2$ decision $\mathbf{d}_{B}=$ $\left(\mathrm{d}_{N / 2}+1, \ldots, \mathrm{d}_{i}, \ldots, \mathrm{d}_{N}\right)$ Supply chain performance is a function of both parties' decisions, formally $P\left(\mathbf{d}_{S}, \mathbf{d}_{B}\right)$, and will be specified next.

To measure a supply chain's overall performance, however, the parties' decisions cannot be considered in isolation. Rather, decisions may interact nontrivially. For instance, a workflow option at the supplier may affect the decision about quality control at the buyer's end. More generally 
speaking, the supply chain's technological anatomy may be highly complex with many interacting decisions or less complex with sparse interactions. In the complex case, we speak of rugged technology landscapes, and in the simpler case of smooth technology landscapes. Formally, interactions between decisions are captured by $K$, the second parameter featured in the standard NK model. Let $p_{i}$ be the performance contribution of each decision that depends not only on its own specification $d_{i}$ but also on the value of $K$ other specifications as signified by the vector $\mathbf{d}_{-i}=\left(\mathrm{d}_{\mathrm{i} 1}, \ldots, \mathrm{d}_{i K}\right)$. Note that the specific interactions may well cut across the firms' boundaries, that is, the contribution of one of the supplier's decisions may depend on one (or more) decisions of the buyer (and vice versa). For every possible specification of $\left(d_{i 1}, \ldots, d_{i K}\right)$, a random draw from a standardized uniform distribution determines the performance contribution $p_{i}\left(d_{i}, \mathbf{d}_{-i}\right)$, that is, $p_{i}\left(d_{i}, \mathbf{d}_{-i}\right) \sim \mathrm{U}[0,1]$. The overall supply chain performance is the average of all supplier and all buyer decisions' contributions. Formally, the overall supply chain performance function $P\left(\mathbf{d}_{S}, \mathbf{d}_{B}\right)$ maps both parties' decisions onto a one-dimensional supply chain performance variable:

$$
\begin{aligned}
\underbrace{P\left(\mathbf{d}_{S}, \mathbf{d}_{B}\right)}_{\begin{array}{l}
\text { Supply chain } \\
\text { performance }
\end{array}} & =\underbrace{P_{B}\left(\mathbf{d}_{S}, \mathbf{d}_{B}\right)}_{\begin{array}{l}
\text { Buyer's } \\
\text { performance }
\end{array}}+\underbrace{P_{S}\left(\mathbf{d}_{S}, \mathbf{d}_{B}\right)}_{\begin{array}{l}
\text { Supplier's } \\
\text { performance }
\end{array}} \\
& =\sum_{i=1}^{N / 2} \frac{p\left(\mathrm{~d}_{i}, \mathbf{d}_{-i}\right)}{N / 2}+\sum_{i=N / 2+1}^{\mathrm{N}} \frac{p\left(\mathrm{~d}_{i}, \mathbf{d}_{-i}\right)}{N / 2} .
\end{aligned}
$$

In each period $t$, the firms carry out search sequentially. Each search randomly chooses one decision $d_{i}$, evaluates if changing specification (from 0 to 1 , or vice versa) improves performance, and updates the configuration in the case of gains. Next, the other firm carries out its search, this cycle being repeated during $T$ periods where $T$ represents the time-to-market pressure of the search.

\subsection{1 | Embedded and deembedded relationships}

Both our literature review and case observation characterize an embedded relationship as attending to the other party's objectives: each firm considers not only how its decisions will affect its own performance but also how its acts will influence the results of the other firm's decisions. For example, in the embedded period, Nissan and the supplier engaged in collaborative kaizen programs that were geared to offer joint gains to both firms. In the model, embedded firms likewise search for supply chain-wide performance improvements on behalf of the supplier's performance objective $O_{S}^{\mathrm{em}}$ and for the buyer's performance objective $O_{B}^{\text {em }}$ formally expressed as:

$$
O_{B}^{\mathrm{em}}\left(\mathbf{d}_{s}, \mathbf{d}_{B}\right)=O_{S}^{\mathrm{em}}\left(\mathbf{d}_{S}, \mathbf{d}_{B}\right)=P\left(\mathbf{d}_{S}, \mathbf{d}_{B}\right) .
$$

In contrast, a deembedded firm gauges solely how its choices will affect its own results. Here, when the supplier and the buyer search the landscape, they will adhere to partial objective functions. As our focal relationship deembedded, Nissan and the supplier strove for improving their own performance by nurturing new capabilities (e.g., modularizing platforms and prototyping, respectively); those initiatives did not aim at improving the supply chain performance between Nissan and the supplier. Formally, when a supplier and a buyer are in a deembedded relationship, the supplier (and the buyer, respectively) evaluate decisions based on internal respective performance objectives $O_{S}^{\mathrm{de}}\left(O_{B}^{\mathrm{de}}\right)$, which are defined by the respective (individual) performances ${ }^{7}$ :

$$
\begin{aligned}
O_{S}^{\mathrm{de}}=P_{S}\left(\mathbf{d}_{S}, \mathbf{d}_{B}\right) & =\sum_{i=1}^{N / 2} \frac{p\left(\mathrm{~d}_{i}, \mathbf{d}_{-i}\right)}{N / 2} \\
& \neq \\
O_{B}^{\mathrm{de}}=P_{B}\left(\mathbf{d}_{S}, \mathbf{d}_{B}\right) & =\sum_{i=N / 2+1}^{N} \frac{p_{i}\left(\mathrm{~d}_{i}, \mathbf{d}_{-i}\right)}{N / 2} .
\end{aligned}
$$

\subsection{2 | The deembedding process}

Deembedding the supply chain refers to shifting a relationship from an embedded (default) state into a deembedded state. When this shift happens, supply chain members no longer search for mutual benefits but only for their own. For a given period $t$, the supply chain becomes deembedded with probability $\delta$-referred to as inclination to deembed. To broaden the perspective from our single case and to unearth the performance tradeoffs tied to varying inclinations to deembed, this strategic variable will be systematically varied such that $\delta \in[0,1]$. As a default in the baseline model, the deembedded supply chain is reembedded (i.e., resumes the embedded state) after one period. However, later we also investigate the duration of deembedding.

Our notion of deembedding as a tunable probability has three important advantages. First, it provides a parsimonious representation of relationship deembedding free of designing specific policies that is more in-line with ideal agent-based modeling. Second, this representation accords well with the search notion from complexity theory, which argues that organizational decision-making is not perfectly rational, transpiring via simple heuristics such as probabilistic decision rules (Cyert \& March, 1963). Third, as our goal is to characterize supply chain performance effects from a conservative angle, we are chiefly interested in the theoretical advantages and disadvantages of deembedding events that 
may occur stochastically. We thus sidestep having to tailor (perhaps improperly) an "optimal" rule for deembedding the supply chain. In the robustness section, we investigate a model extension that is built around the special case of deembedding contingent on a standstill in performance.

\section{2 | Simulation results}

We implemented the model described above in Matlab and ran 10,000 replications of each experimental instance. When not specified otherwise, we parameterized the NK technology landscape with $N=12$ and $K=6$. While this parameterization clearly does not capture the magnitude and complexity of real-world supply chain decision-making, it allows us to represent sufficiently complex behavior that can still be managed computationally (cf. Chandrasekaran et al., 2015). Allowing for a replication of our results (also through replicative coding in other programming languages), we included a pseudocode of our model in the Appendix B. All presented performance figures are statistically robust in that they exhibit sufficiently small standard errors $(<0.001)$ - too small to be meaningfully displayed in the ensuing performance graphs.

\subsection{1 | The performance implications of deembedding for supply chain search}

Figure 4 shows supply chain performance $(P$, depicted on the $y$-axis) as a function of the (varied) inclination to deembed the relationship ( $\delta$, depicted on the x-axis). The two curves characterize an environment of moderate ( $T=100)$ versus high $(T=50)$ time-to-market pressure. Starting from an ever-embedded supply chain $(\delta=0)$, we observe that a small increase in $\delta$ provides steep performance gains for the supply chain for both time-to-market-pressures. A maximum performance is reached at $\delta=20 \%$ for both time-to-market pressures. High time-to-market pressure, however, takes a toll on performance because less time is available for search. Post-peak performance drops with inclination to deembed the supply chain. While the performance effects are more pronounced for moderate time-to-market pressure, both performance curves trace an inverse U-shaped pattern where a modest, positive inclination to deembed appears most effective.

Why does a temporarily deembedded supply chain search improve overall performance? Search theory has shown that organizational adaptation on complex landscapes may eventually freeze (Rivkin \& Siggelkow, 2003) as organizations reach a "sticking point." In the single organization setting, organizational search halts on a local hill where any small move would deteriorate performance. We also know that freezing on inferior configurations proves more likely and becomes especially damaging when organizations face more complex search environments on more rugged landscapes (Levinthal, 1997).

In our interorganizational setting that embraces a dyadic relationship of two firms, search activities across the entire supply chain may likewise freeze, particularly when neither buyer nor supplier can identify specific actions that would advance the relationship en bloc. Such a scenario transpired with Nissan and its first-tier suppliers during the overembeddedness period. Here, the supply chain relationship seemed to be stuck in deadlock as evidenced by declining innovation advances in Figure 2. At the same time, it is also possible that deembedding the supply chain relationship reshapes how the supply chain deals with sticking points. To probe this further, we ran another experiment in which we varied the complexity of the supply chain's environment, exploring both lower complexity $(K=2)$ and higher complexity $(K=10)$.

Figure 5 details results of the simulation experiment in which we varied the complexity of the supply chain under moderate time-to-market pressure $(T=100)$. To compare performance across complexity levels, the y-axis plots a relative supply-chain performance gain or loss that a deembedding supply chain (with varying $\delta$ ) has above or below an ever-

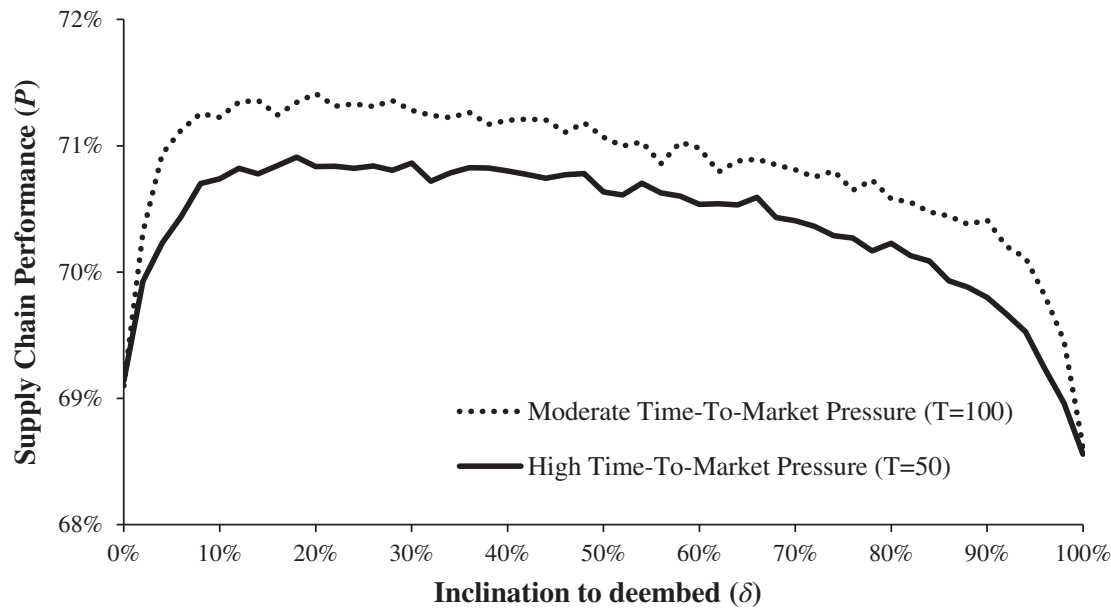

F I G URE 4 Supply chain performance as a function of the inclination to deembed 
F I G URE 5 Performance gains from deembedding under varied complexities

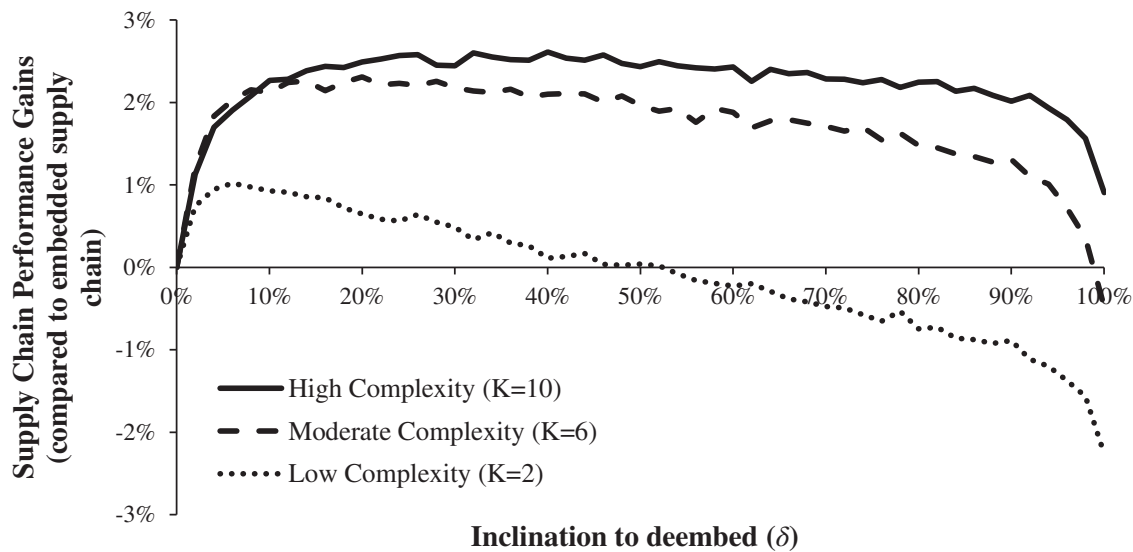

embedded supply chain $(\delta=0)$ facing identical degrees of complexity $(K \in\{2,6,10\})$. This relative perspective allows us to focus on the performance gains delivered by deembedding normalized for each complexity level. Notably, previous research has established that complexity also generally affects performance levels in NK fitness landscapes via (a) different likelihoods for local peaks and valleys, and (b) the various expected performance heights and depths for such local positions (Levinthal, 1997). Therefore, we isolate the effects of deembedding from the other (known) effects of complexity.

Two results from Figure 5 are particularly striking. First, the performance gain from deembedding is higher in environments of higher complexity. This can be seen where the $K=10$ performance curve dominates the $K=6$ performance curve sitting atop the $K=2$ performance curve. Second, the most effective inclination to deembed increases (shifting rightward in Figure 5) with complexity: For $K=2$, it is at about $6 \%$; for $K=6$, gains peak near $20 \%$; for $K=10$, benefits plateau at around $40 \%$. Moreover, for lower levels of complexity, performance gains plunge more quickly with higher deembedding. For $K=2$, increasing the deembedding inclination beyond $50 \%$ would even reduce supply chain performance below that of an ever-embedded supply chain (as signified by performance losses with the high inclination to separate).

The first result highlights that deembedding is more effective when complexity is high, that is, when it is more likely for the supply chain to find itself in deadlock on a local performance hill. In such a scene, deembedding temporarily relaxes the strong ties between the relationship partners. Then, both the supplier and the buyer no longer pursue chain-wide performance but they independently search for self-improvement. By doing so, they make decisions that may harm the supply chain as a whole in the short term while prodding the relationship to escape a local optimum to advance in the long term. Thus, deembedding can broaden the entire supply-chain search. Because the supply chain reembeds after the deembedding, the aligned supply chain partners will again make decisions to smooth out prior misaligned actions. However, the creative impulse obtained from deembedding moves the supply chain forward from past local sticking points. This mechanisms of broadened search well befits the more radical improvement initiatives that Nissan and its suppliers undertook when their relation was deembedded.

The second result highlights that while deembedding may improve supply chain performance, it comes at a cost when used excessively. This cost results from the loss of alignment between the buyers' and suppliers' decisions. As they pursue independent improvements fitting their own objectives, incompatible paths may result. Deembedding costs are embodied in the waning (and even negative) postpeak trajectories in Figure 5. Here, too-frequent deembedding spawns mismatches that hamper supply chain performance. Under low complexity, the advantage of broader search via deembedding is limited, and the cost of deembedding quickly counteracts any benefits.

\subsection{2 | Duration and intensity of deembedding}

So far, we have assumed that deembedding lasts for one period $(D=1)$ where the deembedding features a complete cut of ties between the supplier and buyer. In order to shed light on the effects of both duration and intensity of deembedding, we now relax these two assumptions. First, we let deembedding take a tunable duration of $D>1$ periods, that is, after the firms stay deembedded more than one period before they resume into an embedded relationship (i.e., reembedding). Second, within deembedded periods, the supply chain members will not totally cut ties. Rather, they will entertain a subset of decisions $J \in\{0, \ldots, N\}$ whose contributions may be jointly considered in the respective performance objectives $O_{S}^{\text {de }}$ and $O_{B}^{\text {de }}$ that they seek to improve. Here, the intensity of a deembedding can be characterized by $1-J / N$. When $J=0$, the intensity is $100 \%$ because there is no overlap in the objectives, whereas if $J=N$, intensity is $0 \%$ and the supply chain will stay embedded as the objectives of buyer and supplier match. Figure 6 portrays the results of this relaxation upon supply chain performance for $T=100$ and $K=6$ under tuned duration-intensity combinations. Deembedding is most effective when implemented in the form of short and 


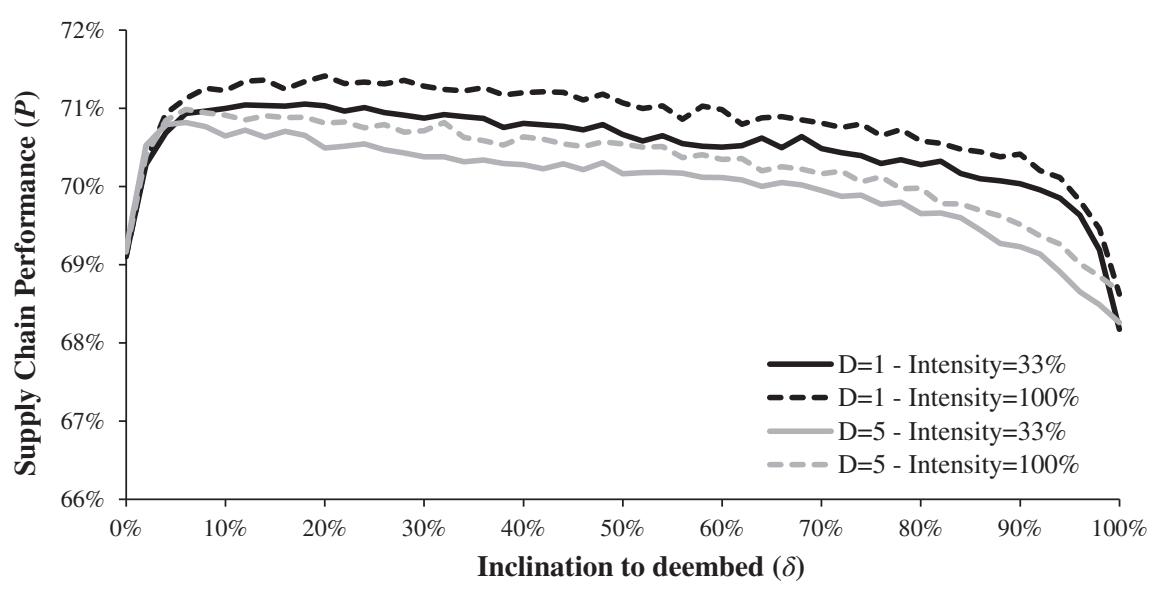

F I G URE 6 Performance gains from deembedding under varied intensities and durations intense periods, as seen for the dominating curve with $D=1$ and $100 \%$ intensity. With a brief, intense deembedding strategy, the supply chain strikes an effective trade-off: the supply chain enjoys creativity unleashed by intense periods of deembedded search, while not losing much time that is required for recoordinating these initiatives through successive reembedding efforts.

To summarize, our simulation reinforces the main finding of the case study; thereby it lends further validity to the simulation model and generalizes our case insights by unearthing how temporary deembedding affects search as a mechanism for supply chain performance (Proposition 1). Furthermore, the simulation-based results augment theory, giving rise to propositions on (a) how frequently deembedding should occur to improve performance (Proposition 2), (b) how technological complexity interacts with the performance gains of deembedding (Proposition 3), and (c) how long and intense the deembedding periods should be (Proposition 4).

\section{Proposition 2: There is an inverted U-shaped relationship between the inclination to deembed and supply chain performance where a small inclination is most effective for supply chain performance.}

Proposition 3: Temporary deembedding is more beneficial to supply chain performance in more complex technology landscapes.

Proposition 4: Short and intense periods of deembedding offer higher performance gains than prolonged or less intense periods of deembedding.

\section{3 | Model extensions and robustness analyses}

In order to address specific "what-if" questions and to broaden the perspective obtained from the case, we explored a number of model extensions. The first extension addresses the question of how deembedding would affect supply chain performance, if it was only triggered in response to a performance standstill. This question is relevant for our case, because although deembedding was motivated by disappointing supply chain wide performances, it was not immediately linked in chronological terms. Only after the alliance with Renault, when it had already been in standstill for nearly a decade, did Nissan trigger deembedding. To examine the special case of deembedding contingent on poor performance, we devised a model extension in which deembedding can only be triggered when there has been no movement in supply chain search and so performance came to a halt in the previous period. Formally, in any period $t$ that follows a performance standstill such that $P\left(\mathbf{d}^{(t-1)}\right)=P\left(\mathbf{d}^{(t-2)}\right)$, deembedding may occur with probability $\delta$. Two important yet intuitively expected implications are obtained from this extension, as illustrated in Figure 7. First, deembedding continues to create value when triggered contingent on standstill (Proposition 1); if implementable, such a practice would even outperform our base model. This is because the supply chain is deembedded just when it can help reinvigorate search. Second, the characteristic performance curve of deembedding remains (Proposition 2), yet its downside part appears less pronounced. This result is because deembedding takes effect only following a performance standstill and so cannot harm efforts to ensure compatibility after deembedding as much.

The second extension examines the counter-factual case of a supplier unwilling and/or incapable to reembed in our case study. We observed in fact that the supplier was initially skeptical to reembed, but eventually joined Nissan's reembedding efforts. Therefore, we devised a model where the supplier stays deembedded even when the buyer reembeds, that is, the supplier's search objective remains the individual goal $O_{S}^{\text {de }}$ rather than reverting back to the supply chain wide goal $O_{S}^{\mathrm{em}}$. Figure 7 illustrates that a supplier unwilling to reembed imposes a deadweight loss on supply chain performance when compared to our base model. 
F I G URE 7 Model extensions

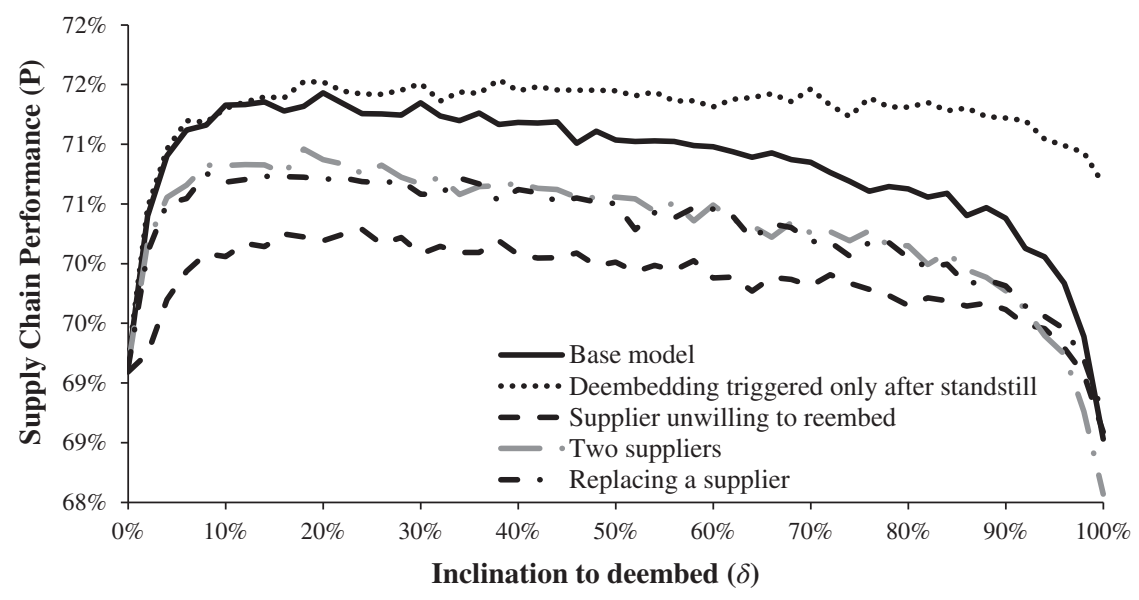

Two factors drive this disadvantage: (a) the supplier's reembedding is required to guarantee compatibility of bilateral search efforts, and (b) future deembedding will be less impactful because the supplier stays deembedded. A way out of this dilemma, one could conjecture, is that the buyer compensates the buyer to reembed, but more field and model-based research is needed to examine that approach.

In our third model extension, we delve into the question of whether our key insights on deembedding remain when considering systemic deembedding (i.e., altering the relations with all suppliers in the supply base) instead of our dyadic focus (affecting only the focal buyer-supplier relationship). We thus deliberately depart from our unit of analysis and extend the simulation model by first incorporating a supply chain with two suppliers (each making $N / 4$ decisions $\mathbf{d}_{S l}$, and $\mathbf{d}_{S 2}$, respectively, while the buyer still owns N/2 decisions $\mathbf{d}_{B}$ ). Building on that first variation, we also devised a second variation where one of the two suppliers may be replaced when deembedding occurs. That means that one of the supplier's configuration $\mathbf{d}_{S 1}$ or $\mathbf{d}_{S 2}$ (with equal chances) may be entirely changed after deembedding. Both variations with two suppliers offer the same inverse U-shaped patterns as regards to supply chain performance (see Figure 7).

To summarize, we examined three relevant what-if scenarios that generalize the contingencies of our case study. While these extensions give rise to intricate performance nuances of deembedding under new scenarios, they all reinforce our key findings regarding the benefits of temporary deembedding and so lend further robustness to our theory building.

\section{6 | GENERAL DISCUSSION}

This research investigates the phenomenon of temporary deembedding as a dynamic strategy to manage supply chain relationships and analyzes how temporary deembedding may influence supply chain performance. A longitudinal case study of Nissan's relationship with a strategic first-tier supplier showed that temporary deembedding reinvigorated both parties' improvement and innovation initiatives to the betterment of the relationship's performance. Evidence from this buyer-supplier case indicates that prior close embedding led to a deadlocked performance that neither partner's innovative efforts could dispel. Deembedding stirred the relationship, enabling both Nissan and the supplier to shape their own improvement initiatives, which enabled the supply chain to break free of its deadlock. Later efforts to reembed the supply chain enhanced coordination that restored the compatibility of distributed initiatives. To validate our case findings and augment our theory building, we forged a parsimonious simulation model using complexity theory and its fundamental notion of search (Levinthal, 1997). The simulation experiments generalize our main finding that benefits arise from temporarily relaxing embeddedness between buyers and suppliers (Proposition 1). The simulations augment this finding in a threefold way. First, deembedding harms supply chain performance when pursued too often (Proposition 2). Second, deembedding benefits supply chain performance especially in environments subject to high technological complexity (Proposition 3). Third, short but intense deembedding is most effective for enhancing supply chain performance (Proposition 4).

\section{1 | Theoretical implications}

Taken together, the case and simulation results feature three contributions to supply chain management research. First, we offer new theoretical insights on how to manage buyersupplier relationships-a research topic hotly debated. For example, Cachon and Lariviere (2005) highlight the supply chain-wide benefits of aligning buyer-supplier aims through revenue-sharing contracts. In a similar vein, Dyer and colleagues argue that embedded relationships comprised the main factor driving the competitive advantage of Japanese manufacturers over their American counterparts (Dyer, 1996; Dyer, 1997; Dyer \& Chu, 2000; Dyer \& Singh, 1998). 
Likewise, research on supply chain innovation advocates close, prolonged involvement of suppliers in new product development processes (e.g., Clark, 1989; Yan \& Dooley, 2013, 2014). In contrast, our case and simulation findings suggest that an overly embedded relationship can impede supply chain innovation and performance. This finding is in-line with later research that has documented excessive embeddedness as a liability (e.g., Gargiulo \& Benassi, 2000; Swink \& Zsidisin, 2006; Villena et al., 2011; Zhou et al., 2014). This latter stream of research concludes that firms should avoid overly embedded ties and strive for a balanced degree of embeddedness. Yet, it has remained unclear how firms can achieve such a balanced level of embeddedness. We contribute to this discussion by building knowledge on how firms, by temporary deembedding their relationships, can dynamically achieve an effective balance. Our study thus challenges the implicit rigidity assumption that has plagued SCM and so opens up a new research avenue that conceptualizes buyersupplier embeddedness as a dynamic phenomenon.

Second, we link our notion of dynamic embedding to the concept of search from complexity theory. We do so by demonstrating how temporary deembedding influences trajectories and outcomes of supply chain-wide search in our case and simulation. Prior research on the dark side of embedded relationships proposes excessive opportunistic behavior as an explanation for the detrimental effects of over-embeddedness (Gargiulo \& Benassi, 2000; Villena et al., 2011). In contrast, our search perspective suggests that even when supply chain members attend to each other's needs perfectly free of opportunism, embeddedness beyond a certain threshold locks both organizations into improvement initiatives that offer mutually acceptable, yet only incremental, performance improvements. Our search perspective also qualifies prior research that seeks to optimize supply chain relationships through formal models (e.g., Cachon \& Lariviere, 2005). Due to the complexity of supply chain decision-making, it is oftentimes difficult-if not impossible - to formulate "optimal" masterplans for buyersupplier relationships. Instead, the search perspective acknowledges this complexity and conceptualizes supply chains as a setting where imperfectly rational decision-makers jointly and iteratively search for improvements and innovations (e.g., Chandrasekaran et al., 2015; Giannoccaro, 2011; Kim et al., 2015; Sting \& Loch, 2016).

Third, our view explicitly recognizes the agency of firms in deliberately and strategically tuning their supply chain relationships. Prior research associates a level of embeddedness with performance outcomes, or sees embeddedness as evolving only within a natural course. For example, Jap and Anderson (2007) and Vanpoucke et al. (2014) empirically tested how relationship characteristics vary across predefined phases of a relationship's life-cycle. Saavedra et al. (2008) and Burt $(2001,2002)$ investigated gradually diminishing relationships

over time. These approaches assume structurally determined embeddedness: firms' relationships with suppliers either remain relatively stable or evolve in a presaged course that leaves little room for endogenous relationship changes. By contrast, we propose an agency view of buyer-supplier ties, which conceptualizes firms as strategic players actively shaping their relationships. This view pioneers new research paths for exploring change in supply chain interactions as an endogenous and discretionary process.

\section{2 | Managerial implications}

Our study offers important insights for managerial practice. These insights follow directly from the propositions put forth in this article, as shown in Table 2. First, supply chain managers do not have to view embeddedness as a one-time choice. Rather, they can revise the embeddedness of buyer-

T A B L E 2 Linking propositions with managerial implications

\section{Theoretical finding (propositions) \\ Temporary relaxation of buyer-supplier embeddedness can aid overall supply chain performance via reinvigorated improvement and innovation initiatives.}

There is an inverted U-shaped relationship between the inclination to deembed and supply chain performance where a small inclination is most effective for supply chain performance.

Temporary deembedding is more beneficial to supply chain performance when technology landscapes are more complex.

Short and intense periods of deembedding offer higher performance gains than prolonged or less intense periods of deembedding.

\section{Managerial implication}

Managers do not have to view supply chain embeddedness as a one-time choice but as a dynamic and malleable process over which they have agency.

Temporary deembedding should be adopted as a strategic tool of buyersupplier relationship management.

Temporary deembedding can offer supply chain wide innovation gains, but too much deembedding causes supply chain incompatibilities.

Despite the received wisdom that "more complexity calls for more coordination," close coordination under complexity might actually "freeze" the relationship in a deadlock. Deembedding (and so temporarily reduced coordination) can break this.

Deembedding is most effective when executed in a short and intense way. 
supplier relationships dynamically. Our study notably shows how temporary deembedding can reinvigorate capability improvements which, in turn, can benefit supply chain performance. As illustrated in our case study, firms can deembed by selling their equity holdings in the supplier; dedicating purchasers to components rather than to suppliers; diversifying business across several alternative suppliers; curbing close friendships with suppliers, and; clarifying standards that govern the relationship, among many other measures. Firms need to reverse such structural and relational efforts when reembedding. However, reembedding in the cognitive dimension can be particularly difficult. This dimension encompasses shared meaning, defined rules, and set roles in the relationship. When these are altered drastically as part of intense deembedding, resumed realignment may not be straightforward.

Second, our investigation of the duration, intensity, and frequency of temporary deembedding can also inform supply chain decision-making. Intuition calls for more coordination between supply chain members in more complex environments. This is due to increased technological interdependence among decisions of buyers and suppliers. Our results qualify this intuition by adding a dynamic perspective. Particularly in complex environments, the supply chain's search for innovation is more likely to get stuck because there are more technological interdependencies to consider, which further paralyze search. Deembedding the relationship can thus offer additional performance benefits due to its ability to unleash innovation by all supply chain members. By temporarily deembedding interdependent efforts at the buyer and supplier, supply chain management can strike an effective balance between the coordination advantages of tight collaboration (in an embedded relationship) and the innovation advantages of distributed initiatives (in a temporary deembedded relationship). Yet, engaging in deembedding too frequently or staying deembedded for too long leads to incompatible search outcomes, which in turn can hurt supply chain performance.

\section{3 | Limitations}

The main limitation of our study is that our inductive case study relied on one specific buyer-supplier relationship. In order to triangulate how embeddedness evolved over time and to strengthen internal validity of our case findings, we incorporated secondary data (e.g., equity ownership in the supplier and patent data). These secondary data show patterns consistent to what we find in our case. Furthermore, we confirmed with our Nissan interviewees that our observations were not specific to the particular component we studied. Most importantly, our research design combines an inductive case study with agent-based simulations in order to generalize and augment our understanding of the deembedding phenomenon and its mechanisms.

Moreover, at first glance it seemed that Nissan reacted to poor supply chain performance by deembedding the relationship with the supplier. However, our analysis suggests that a timely response was not the case. In fact, supply chain performance had been ailing for several years before the NRP. Therefore, without making strong assumptions about the ability to detect poor performance, the base model describes a process that may repeatedly probe the relationship. The model, consequently, offers the generalizable and robust insight that short but intense temporary deembedding improves supply chain performance even under imperfect monitoring and response. In our model extension, we observe that performance-contingent deembedding would boost performance even further. A repeated probing of relationships gives rise to a dynamic pattern of punctuated equilibria; where periods of standstill are trailed by periods of reinvigorated search. That said, more field and modeling research is needed to fully understand whether, and if so, how, the timing of deembedding can be optimized.

Finally, absent broader cross-industry and cross-country analyses that empirically test and further generalize our conclusions, our advice on deembedding should be considered with caution. Still, we are confident that our findings pave the way for scholars to develop further insights to support the dynamic and malleable view of buyer-supplier relationships that we propose here.

\section{ENDNOTES}

${ }^{1}$ We reviewed all articles on buyer-supplier relationships published between 2006 and 2016 in leading operations and management journals: Journal of Operations Management, Production and Operations Management, International Journal of Operations \& Production Management, Management Science, Strategic Management Journal, Academy of Management Journal, and Administrative Science Quarterly.

${ }^{2}$ The dyad discussed in this article is part of a larger data set consisting of Nissan; seven of its first-tier suppliers; and two of its second-tier suppliers that was used in Stevens et al., 2015 to discuss trust in buyer-supplier relationships.

${ }^{3} \mathrm{Ke} i$ is used to signal group membership. It is the same Japanese character $k e i$ as the first syllable in keiretsu, and means "linked." Looked at from the supplier perspective, this affiliation is exclusive; suppliers are not affiliated with more than one OEM. It is based on the history of the supplier and generally does not change over time, even when the customer base of the supplier changes.

${ }^{4}$ Stiff competition and surging demand forced Nissan to reluctantly purchase this technology from its major competitor Toyota. Nissan's first hybrid electric vehicle, the Nissan Altima hybrid, was introduced in 2007 carrying the Toyota technology.

${ }^{5}$ Due to the global financial crisis, GT2012 was suspended by Nissan less than a year later in February 2009. 
${ }^{6}$ To honor the supplier's request to remain anonymous, we do not disclose its profits and revenues here.

${ }^{7}$ Note that, as a result, deembedding does not constrain the firms' search scope but only their objectives. That is, formally, both firms always search on all of their N/2 decisions. This representation is grounded in our case relationship, where neither member's search domain was affected by the deembedding or by reembedding.

\section{REFERENCES}

Aoki, K., \& Lennerfors, T. T. (2013). The new, improved keiretsu. Harvard Business Review, 91, 109-114.

Azoulay, P., Repenning, N. P., \& Zuckerman, E. W. (2010). Nasty, brutish, and short: Embeddedness failure in the pharmaceutical industry. Administrative Science Quarterly, 55, 472-507.

Barratt, M., Choi, T. Y., \& Li, M. (2011). Qualitative case studies in operations management: Trends, research outcomes, and future research implications. Journal of Operations Management, 29, 329-342.

Boyer, K. K., \& Swink, M. L. (2008). Empirical elephants-Why multiple methods are essential to quality research in operations and supply chain management. Journal of Operations Management, 26, 338-344.

Burt, R. S. (2001). Attachment, decay, and social network. Journal of Organizational Behavior, 22, 619-643.

Burt, R. S. (2002). Bridge decay. Social Networks, 24, 333-363.

Cachon, G. P., \& Lariviere, M. A. (2005). Supply chain coordination with revenue-sharing contracts: Strengths and limitations. Management Science, 51, 30-44.

Carey, S., Lawson, B., \& Krause, D. R. (2011). Social capital configuration, legal bonds and performance in buyer-supplier relationships. Journal of Operations Management, 29, 277-288.

Chandrasekaran, A., Linderman, K., Sting, F. J., \& Benner, M. J. (2015). Managing R\&D project shifts in high-tech organizations: A multi-method study. Production and Operations Management, 24, 560-586.

Chen, I. J., \& Paulraj, A. (2004). Towards a theory of supply chain management: The constructs and measurements. Journal of Operations Management, 22, 119-150.

Choi, T. Y., \& Kim, Y. (2008). Structural embeddedness and supplier management: A network perspective. Journal of Supply Chain Management, 44, 5-13.

Chopra, S., \& Meindl, P. (2007). Supply chain management: Strategy, planning \& operation. Upper Saddle River, NJ: Prentice Hall.

Clark, K. B. (1989). Project scope and project performance: The effect of parts strategy and supplier involvement on product development. Management Science, 35, 1247-1263.

Clark, K. B., \& Fujimoto, T. (1991). Product development performance: Strategy, organization, and management in the world auto industry. Boston, MA: Harvard Business Press.

Cohen, W. M. (2010). Fifty years of empirical studies of innovative activity and performance. Handbook of the Economics of Innovation, 1, 129-213.

Cousins, P. D., Handfield, R. B., Lawson, B., \& Petersen, K. J. (2006). Creating supply chain relational capital: The impact of formal and informal socialization processes. Journal of Operations Management, 24, 851-863.
Cousins, P. D., \& Menguc, B. (2006). The implications of socialization and integration in supply chain management. Journal of Operations Management, 24, 604-620.

Cusumano, M. A. (1985). The Japanese automobile industry: Technology and management at Nissan and Toyota. Cambridge, MA: Harvard University Press.

Cyert, R. M., \& March, J. G. (1963). A behavioral theory of the firm. Englewood Cliffs, NJ: Prentice Hall.

Dyer, J. H. (1996). Does governance matter? Keiretsu alliances and asset specificity as sources of Japanese competitive advantage. Organization Science, 7, 649-666.

Dyer, J. H. (1997). Effective interfirm collaboration: How firms minimize transaction costs and maximize transaction value. Strategic Management Journal, 18, 535-556.

Dyer, J. H., \& Chu, W. (2000). The determinants of trust in supplierautomaker relationships in the US, Japan and Korea. Journal of International Business Studies, 31, 259-285.

Dyer, J. H., \& Singh, H. (1998). The relational view: Cooperative strategy and sources of interorganizational competitive advantage. Academy of Management Review, 23, 660-679.

Gargiulo, M., \& Benassi, M. (2000). Trapped in your own net? Network cohesion, structural holes, and the adaptation of social capital. Organization Science, 11, 183-196.

Giannoccaro, I. (2011). Assessing the influence of the organization in the supply chain management using $\mathrm{NK}$ simulation. International Journal of Production Economics, 131, 263-272.

Giannoccaro, I., \& Nair, A. (2016). Examining the roles of product complexity and manager behavior on product design decisions: An agent-based study using NK simulation. IEEE Transactions on Engineering Management, 63, 237-247.

Gioia, D. A., Corley, K. G., \& Hamilton, A. L. (2012). Seeking qualitative rigor in inductive research notes on the Gioia methodology. Organizational Research Methods, 16, 15-31.

Granovetter, M. S. (1973). The strength of weak ties. American Journal of Sociology, 78, 1360-1380.

Gulati, R., \& Sytch, M. (2007). Dependence asymmetry and joint dependence in interorganizational relationships: Effects of embeddedness on a manufacturer's performance in procurement relationships. Administrative Science Quarterly, 52, 32-69.

Ibison, D. \& Fifield, A. (2004). Steel crisis may force more Nissan cuts". Financial Times

Itoh, R. (2001). Goon ga Idomu Nanatsu no Byou: Nissan no Kigyou Kaikaku [seven illnesses that Ghosn challenges: Corporate reform of Nissan]. Tokyo, Japan: Nikkei Business Press.

Jap, S. D., \& Anderson, E. (2007). Testing a life-cycle theory of cooperative interorganizational relationships: Movement across stages and performance. Management Science, 53, 260-275.

Kauffman, S. A. (1993). The origins of order: Self-organization and selection in evolution. New York, NY: Oxford University Press.

Kim, Y., Choi, T. Y., \& Skilton, P. F. (2015). Buyer-supplier embeddedness and patterns of innovation. International Journal of Operations \& Production Management, 35, 318-345.

Langley, A. (1999). Strategies for theorizing from process data. Academy of Management Review, 24, 691-710.

Lawson, B., Tyler, B. B., \& Cousins, P. D. (2008). Antecedents and consequences of social capital on buyer performance improvement. Journal of Operations Management, 26, 446-460.

Levinthal, D. A. (1997). Adaptation on rugged landscapes. Management Science, 43, 934-950. 
Levinthal, D.a., \& March, J. G. (1993). The myopia of learning. Strategic Management Journal, 14, 95-112.

Levinthal, D. A., \& Warglien, M. (1999). Landscape design: Designing for local action in complex worlds. Organization Science, 10, 342-357.

Mayer, B. \& Klein, C. (2015). BMW-Vorstand Zipse: "Produktion kommt von produkt"

Mikawa, T. \& Okudaira, K. (2005, January 24). Ghosn recasting keiretsu suppliers. Nikkei Weekly (Online).

Nahapiet, J., \& Ghoshal, S. (1998). Social capital, intellectual capital, and the organizational advantage. Academy of Management Review, 23, 242-266.

Nair, A., Narasimhan, R., \& Choi, T. Y. (2009). Supply networks as a complex adaptive system: Toward simulation-based theory building on evolutionary decision making. Decision Sciences, 40, 783-815.

Nezu, R. (2000). Carlos Ghosn: Cost controller or keiretsu killer. OECD Observer, 220, 17-19.

Nikkei Industry Journal. (2005, January 13). Paatonaa tsukuri: Tetsu ga kabe [Forging partnerships: Iron is the wall].

Nishiguchi, T. (1994). Strategic industrial sourcing: The Japanese advantage. New York, NY: Oxford University Press.

Orton, J. D., \& Weick, K. E. (1990). Loosely coupled systems: A reconceptualization. Academy of Management Review, 15, 203-223.

Rivkin, J. W., \& Siggelkow, N. (2003). Balancing search and stability: Interdependencies among elements organizational design. Management Science, 49, 290-311.

Saavedra, S., Reed-Tsochas, F., \& Uzzi, B. (2008). Asymmetric disassembly and robustness in declining networks. PNAS, 105, 16466-16471.

Sako, M., \& Helper, S. (1998). Determinants of trust in supplier relations: Evidence from the automotive industry in Japan and the United States. Journal of Economic Behavior \& Organization, 34, 387-417.

Siggelkow, N., \& Rivkin, J. W. (2005). Speed and search: Designing organizations for turbulence and complexity. Organization Science, 16, 101-122.

Simon, H. A. (1962). The architecture of complexity. Proceedings of the American Philosophical Society, 106, 467-482.

Stevens, M., MacDuffie, J. P., \& Helper, S. (2015). Reorienting and recalibrating inter-organizational relationships: Strategies for achieving optimal trust. Organization Studies, 36, 1237-1264.

Sting, F. J., \& Loch, C. H. (2016). Implementing operations strategy: How vertical and horizontal coordination interact. Production and Operations Management, 25, 1177-1193.
Sugiyama, Y. (2002). Transforming knowledge into strategic action: An explorative study on the process of Nissan's recovery. In 18th EGOS Conference, Barcelona, Spain.

Swink, M., \& Zsidisin, G. (2006). On the benefits and risks of focused commitment to suppliers. International Journal of Production Research, 44, 4223-4240.

Terpend, R., Tyler, B. B., Krause, D. R., \& Handfield, R. B. (2008). Buyer-supplier relationships: Derived value over two decades. Journal of Supply Chain Management, 44, 28-55.

Thompson, J. D. (1967). Organizations in action: Social science bases of administrative theory. New York, NY: Transaction Publishers.

Uzzi, B. (1996). The sources and consequences of embeddedness for the economic performance of organizations: The network effect. American Sociological Review, 61, 674-698.

Uzzi, B. (1997). Social structure and competition in interfirm networks: The paradox of embeddedness. Administrative Science Quarterly, 42, 35-67.

Vanpoucke, E., Vereecke, A., \& Boyer, K. K. (2014). Triggers and patterns of integration initiatives in successful buyer-supplier relationships. Journal of Operations Management, 32, 15-33.

Villena, V. H., Revilla, E., \& Choi, T. Y. (2011). The dark side of buyer-supplier relationships: A social capital perspective. Journal of Operations Management, 29, 561-576.

Williamson, O. E. (1985). The economic Intstitutions of capitalism. New York, NY: The Free Press.

Yan, T., \& Dooley, K. (2014). Buyer-supplier collaboration quality in new product development projects. Journal of Supply Chain Management, 50, 59-83.

Yan, T., \& Dooley, K. J. (2013). Communication intensity, goal congruence, and uncertainty in buyer-supplier new product development. Journal of Operations Management, 31, 523-542.

Zhou, K. Z., Zhang, Q., Sheng, S., Xie, E., \& Bao, Y. (2014). Are relational ties always good for knowledge acquisition? Buyer-supplier exchanges in China. Journal of Operations Management, 32, 88-98.

How to cite this article: Sting FJ, Stevens M, Tarakci M. Temporary deembedding buyer - supplier relationships: A complexity perspective. J Oper Manag. 2019;65:114-135. https://doi.org/10.1002/ joom. 1008 


\section{APPENDIX A : INTERVIEW QUESTIONS}

1. What is the main part/system your department purchases from your suppliers?

2. How many Nissan employees are currently in the RNPO supplier panel of this part?

3. How many suppliers are currently in the panel for this part/system?

4. What percentage of sourcing of this part/system is done by your main supplier?

5. In what year did your relation with the supplier start?

6. Please comment on your main reasons for selecting the supplier.

7. In what way is Nissan involved in the design of this part/system?

8. In what way is Nissan involved in the manufacturing of this part/system?

9. In what way is the supplier involved in the design of this part/system?

10. In what way is the supplier involved in the manufacturing of this part/system?

11. Do face-to-face meetings take place between Nissan and the supplier? If so, how often, and which departments/divisions participate in these meetings?

12. If you have a contract with the supplier, could you please indicate the duration (in months or years) as well as the main outline of this contract?

13. Does Nissan provide the supplier with raw materials?

14. Does Nissan provide the supplier with equipment?

15. Does Nissan provide the supplier with management training?

16. Does Nissan provide the supplier with technical training?

17. Does Nissan provide the supplier with financial support?

18. Do joint improvement projects take place between Nissan and the supplier?

19. Does joint product design take place between Nissan and the supplier?

20. Please indicate the degree of financial participation of Nissan in the supplier.

21. Please indicate the extent of dedication of the assets of the supplier to Nissan.

22. If you have a formal contract with the supplier, please indicate its importance.

23. What is the level of integration of IT systems between Nissan and the supplier (for example ERP)?

24. Please comment on your main reasons for selecting the supplier.

25. Does Nissan invite the supplier to meetings such as kyoryokukai?

26. Did you ask the supplier for extra-contractual cost reductions in the past ten years? If so, how did the supplier succeed in achieving these? Did your company assist the supplier?

27. Does Nissan share cost savings resulting from joint improvements with the supplier?

28. Does Nissan reimburse raw material costs to the supplier in case orders are cancelled?

29. To what extent is the supplier responsive to change in its relation with Nissan?

30. To what extent is Nissan responsive to change in its relation with the supplier?

31. To what extent is the supplier willing to invest in the QCD performance of Nissan?

32. To what extent is Nissan willing to invest in the QCD performance of the supplier?

33. Please indicate the level of dedication of the supplier to its relation with Nissan.

34. Please indicate the level of dedication of Nissan to its relation with the supplier. 


\section{APPENDIX B : PSEUDOCODE OF THE NK MODEL SIMULATION}

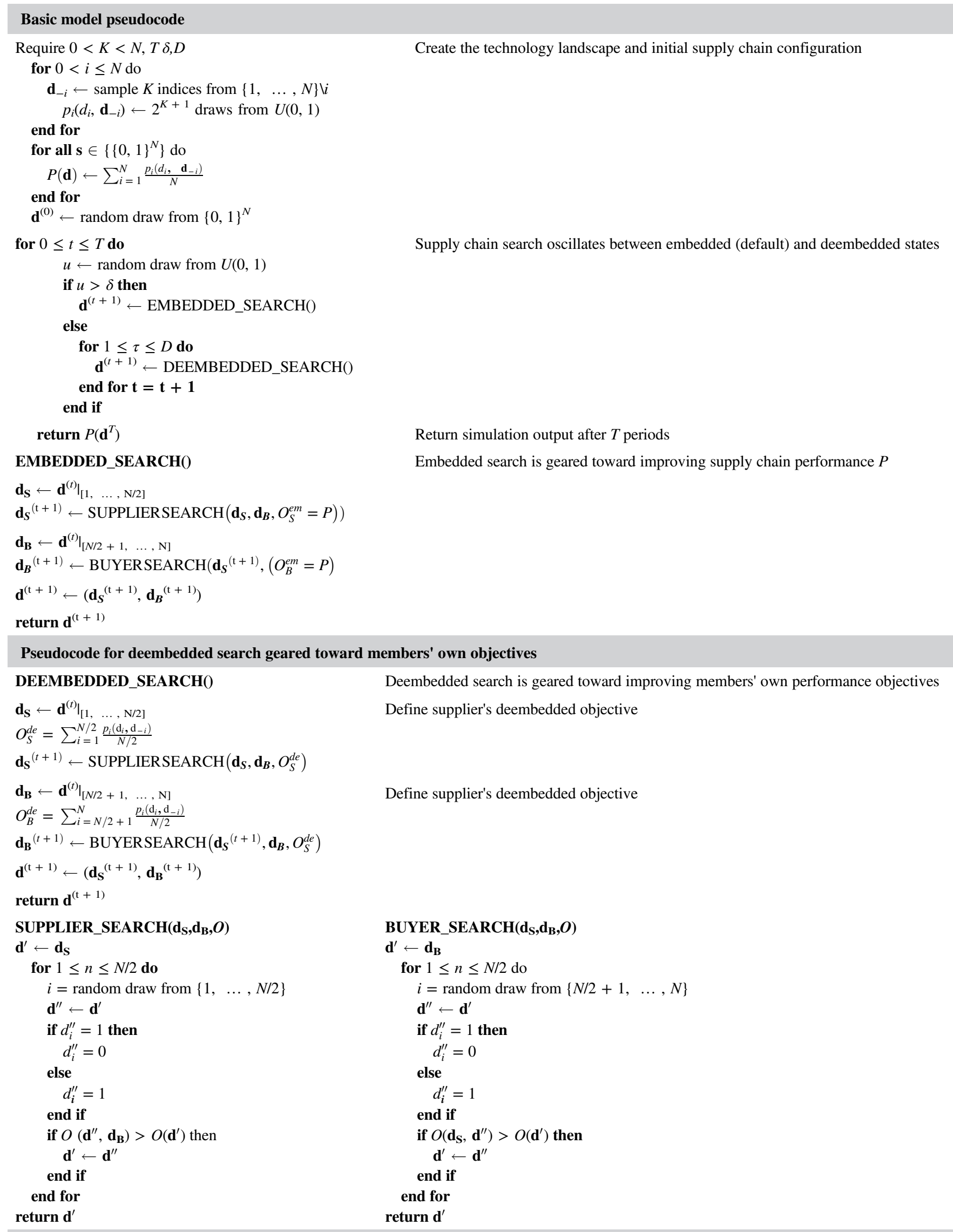

